\title{
CHROMOSOME PAIRING IN AUTOTETRAPLOID BOMBYX MALES. INHIBITION OF MULTIVALENT CORRECTION BY CROSSING OVER
}

by

\author{
SØREN WILKEN RASMUSSEN
}

Department of Physiology, Carlsberg Laboratory
Gamle Carlsberg Vej 10, DK-2500 Copenhagen Valby

Keywords: Meiosis, Synaptonemal complex

Chromosome pairing and synaptonemal complex (SC) formation have been analysed on spread and silver stained chromosome complements from autotetraploid Bombyx spermatocytes $(4 \mathrm{n}=112)$.

The establishment of distant subtelomeric associations between homologous chromosomes previously shown to precede SC formation in diploid Bombyx spermatocytes is also found in the tetraploid spermatocytes. Specific associations can form on either side of a chromosome leading to $\mathrm{SC}$ formation between three or all four homologues. In an animal with aberrant meiosis homologous associations were infrequent or absent resulting in almost random SC formation.

A mean of 13.3 quadrivalents and 25.1 bivalents was present at zygotene while in pachytene complements the mean of quadrivalents was reduced to 8.7 and that of bivalents correspondingly increased to 37.1 . It is concluded 1) that chromosome pairing and SC formation during zygotene combine the four homologues at frequencies approaching the theoretical maximum of $67 \%, 2$ ) that the initial pairing is optimized during the zygotene-pachytene transition to yield a maximum of bivalents and 3 ) that the occurrence of crossing over at pachytene effectively prevents conversion of multivalents into bivalents. A reduction of quadrivalent frequency occurs also between pachytene and metaphase I probably due to bivalent and trivalent - univalent formation when the SC is resolved and suitable chiasmata are absent to hold the four chromosomes together. These and earlier observations on chromosome pairing in the male silkworm are compared and compiled into a flow-chart summarising the events of chromosomes pairing as deduced from ultrastructural analysis.

\section{INTRODUCTION}

Meiosis in polyploid organisms has been studied in a large number of light microscopical investigations $(7,22,23,28,29,45)$ and more recently by ultrastructural work based on serially sectioned or spread chromosome complements $(4,10,11,12,15,24,25,34,36)$. Most of these studies reflect the abundant occurrence of polyploidy in plants, either natural or induced by chromosome doubling of diploids or interspecific hybrids.

Polyploidy in animals, on the other hand, is rare, one of the few well investigated examples being the experimentally induced polyploidy in the silkworm, Bombyx mori. (An excellent discussion of the remarkable difference between the frequency of polyploidy in the plant and animal kingdoms can be found in Astaurov, 1).

It is unlikely that the rare occurrence of polyploidy in animals is related to the meiotic division per se. It has been shown in detailed ultrastructural analyses that the individual processes comprising the meiotic prophase (i.e. synapsis, synaptonemal complex formation,

Abbreviations: $\mathrm{LC}=$ lateral component; $\mathrm{SC}=$ synaptonemal complex. 
crossing over, chiasma formation and disjunction) progress in essentially the same way in normal diploid plants and animals as far as can be assessed by morphological criteria (cf. 9,48 ).

As pointed out previously (37) the silkworm is a favorable experimental system for the analysis of the meiotic prophase. In addition to the possibility of obtaining polyploids of both sexes, crossing over and chiasma formation do not occur in the heterogametic female sex of the silkworm $(42,26)$. Instead, the synaptonemal complexes (SC) in oocytes remain bound to the homologues, and in modified form continue to hold the homologues together until their disjunction at anaphase I, thereby replacing crossing over and chiasma formation in maintaining the association of homologues beyond pachytene $(32,33)$. In the male meiosis the SCs are eliminated after pachytene, the homologues being held together by chiasmata (16) as is normally the case in recombination proficient organisms. The silkworm thus provides a unique opportunity to study the effect of crossing over and chiasma formation on the pairing behaviour of multiple copies of homologues during the meiotic prophase.

Previous ultrastructural analyses of synapsis and synaptonemal complex formation in autotriploid $(3 n=84)$ and autotetraploid $(4 n=$ $112)$ Bombyx oocytes $(34,36)$ revealed a strictly specific pairing of homologous chromosomes into bivalents and multivalents during the first part of zygotene. This pairing pattern was dramatically changed in pachytene nuclei: The number of multivalents became small or zero, while the number of bivalents approached the theoretical maximum of 28 in the triploid and 56 in the tetraploid. The chromosomes of the third set in the triploid were either foldback paired, formed nonhomologous associations of two or more chromosomes, or were present as univalents.

Based on these observations it was concluded $(34,36)$ that the complete or almost complete conversion of multivalents into bivalents reflects an instability of the central region of the SC in chromosome segments where exchange of pairing partner has occurred. This instability was suggested to promote turnover of the central region of the $\mathrm{SC}$ shifting the site of pairing partner exchange towards the telomeres, so that trivalents are converted into a bivalent and a univalent, and quadrivalents into two bivalents. A residual capacity for synapsis and SC formation in the triploid finally accounts for the various nonhomologous associations.

Triploid Bombyx females produce unbalanced gametes, each containing one complete genome plus a varying fraction of the third genome, and are sterile. Tetraploid females, on the other hand, exhibit an almost regular disomic segregation, are fertile and produce viable (but sterile) triploid offspring when crossed to diploid males (2). Comparable ultrastructural analyses of chromosome pairing and its correction at zygotene and pachytene in polyploids of the recombination proficient Bombyx male have so far not been available.

It is the aim of the present study to determine the frequency of bivalents and multivalents at zygotene and pachytene in tetraploid Bombyx spermatocytes and to monitor the initial specific synapsis as well as the subsequent modification of pairing and $\mathrm{SC}$ formation.

Results described below demonstrate that in the tetraploid Bombyx male, multivalents form during the early specific pairing phase at frequencies approaching the theoretical maximum expected if SC formation occurs with equal probability between any two LCs at each end of a chromosome quartet. Conversion of multivalents into bivalents takes place at the zygotenepachytene transition. At pachytene when crossing over occurs (16), multivalents not yet converted into bivalents are fixed by crossovers and can then no longer be converted.

During the specific pairing at zygotene three or even all four homologues are frequently associated at the telomeres, demonstrating that each chromosome at a given region has at least two sites for specific recognition and that both sites can be utilized simultaneously.

Finally, a single tetraploid silkworm was found in which the specific recognition between homologous chromosomes appeared to be defective leading to almost random pairing and SC formation at early zygotene. This supports the notion (35) that recognition between homologues and subsequent SC formation are separate processes. 
Table I. Mean lateral component length per genome for di- and polyploid Bombyx oocytes and spermatocytes.

Late zygotene $\quad$ Early pachytene Mid-late pachytene Reference

$(\mu \mathrm{m}) \quad(\mu \mathrm{m}) \quad(\mu \mathrm{m})$

Oocytes

$\begin{array}{llllll}\text { Diploid (R) } & - & 196(4) & 212(6) & 32 \\ \text { Triploid (R) } & - & 137(4) & 171(7) & 34 \\ \text { Tetraploid (R) } & - & 150(7) & 133(11) & 36\end{array}$

Spermatocytes

$\begin{array}{llllll}\text { Diploid } & (\mathrm{R}) & 202(8) & 198(16) & 257(14) & 16 \\ \text { Diploid (S) } & 219(270) & 213(40) & 215(85) & 35 \\ \text { Tetraploid (S) } & 185(33)^{\prime} & 190(27)^{2} & 186(27)^{3} & \end{array}$

Numbers in paranthesis are the number of nuclei analysed. R, reconstructed complements. S, spread complements. 1) $66-95 \%$ pairing. 2) $95-99 \%$ pairing. 3) $99-100 \%$ pairing.

\section{MATERIALS AND METHODS}

The silkworms (hybrids between strain Lyon 200 and 300 ) were kindly provided by Professor J.M. LEGAY, Laboratoire de Biométrie, Université Claude Bernard, France. Since 1982 the hybrids have been maintained as a random breeding population in the laboratory on an artificial diet (Silkmate E, Nihon Nosan Kogyo KK, Japan). Hatching of diapause eggs stored for up to 6 months at $5{ }^{\circ} \mathrm{C}$ was induced by incubation in $16 \% \mathrm{HCl}$ at $46^{\circ} \mathrm{C}$ for 6-7 $\min (39)$. The eggs hatched 10-14 days later.

Table II. Mean number of chromosome associations in tetraploid Bombyx spermatocytes at $66-95 \%$ pairing.

\begin{tabular}{|c|c|c|c|c|c|c|c|c|}
\hline & $\begin{array}{l}\text { Number } \\
\text { of } \\
\text { nuclei }\end{array}$ & $\begin{array}{l}\text { LC length } \\
\text { of one } \\
\text { genome } \\
(\mu \mathrm{m})\end{array}$ & $\begin{array}{l}\text { Percent } \\
\text { pairing }\end{array}$ & $\begin{array}{l}\text { Uni- } \\
\text { valents }\end{array}$ & $\begin{array}{l}\mathrm{Bi}- \\
\text { valents }\end{array}$ & $\begin{array}{l}\text { Tri- } \\
\text { valents }\end{array}$ & $\begin{array}{l}\text { Quadri- } \\
\text { valents }\end{array}$ & $\begin{array}{l}\text { Other } \\
\text { associ- } \\
\text { ations }\end{array}$ \\
\hline Animal $1^{1}$ & $15 / 13$ & & & & & & & \\
\hline Mean & & 170 & 86 & 1.5 & 23.6 & 1.3 & 13.7 & 0.7 \\
\hline S.D. & & 11 & - & - & 3.6 & - & 2.6 & - \\
\hline Range & & $151-183$ & $66-94$ & $0-9$ & $18-30$ & $0-9$ & $7-18$ & $0-2$ \\
\hline Animal $2^{2}$ & 12 & & & & & & & \\
\hline Mean & & 190 & 83 & 1.2 & 23.2 & 0.6 & 14.1 & 0.8 \\
\hline S.D. & & 11 & - & - & 5.4 & - & 2.7 & - \\
\hline Range & & $178-214$ & $75-93$ & $0-5$ & $15-31$ & $0-2$ & $11-18$ & $0-1$ \\
\hline Animal 3 & 8 & & & & & & & \\
\hline Mean & & 203 & 94 & 0 & 33.3 & 0 & 11.4 & 0 \\
\hline S.D. & & 15 & - & - & 3.7 & - & 2.8 & - \\
\hline Range & & $179-218$ & $92-95$ & - & $30-39$ & - & 9.13 & - \\
\hline Total & $35 / 33$ & & & & & & & \\
\hline Mean & & 185 & 87 & 1.0 & 25.1 & 0.7 & 13.3 & - \\
\hline S.D. & & 18 & - & - & 7.1 & - & 2.7 & - \\
\hline Range & & $151-218$ & $66-95$ & $0-9$ & $18-39$ & $0-9$ & $7-18$ & - \\
\hline
\end{tabular}

1) Carries translocation 1. Total complement length could not be accurately determined for 2 nuclei.

2) Carries translocation 2. S.D., standard deviation. 


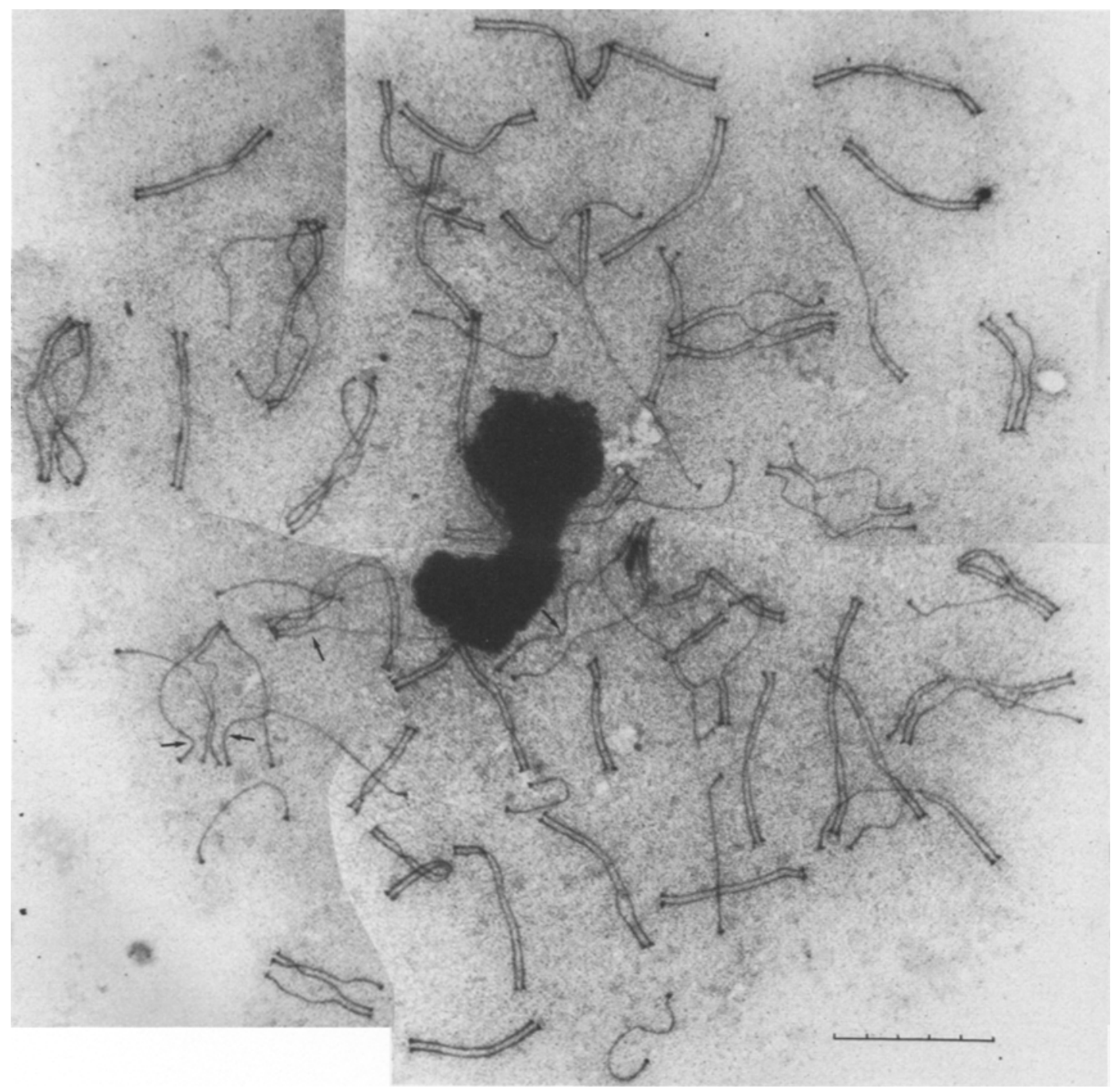

Tetraploid males were obtained as described by KaWAMURA $(19,20,21)$ by exposing $120-130$ min old eggs to low temperature $\left(-10^{\circ} \mathrm{C}\right)$ for 24 h. Subsequent hatching was induced by $\mathrm{HCl}$ treatment as described above. Two to four days later, when the serosa cells had become pigmented the tetraploid eggs were identified by the larger cellular and nuclear diameter of their serosa cells.

Spread chromosome complements were prepared, stained and measured as described previously (35). Altogether 113 normal autotetraploid nuclei from three animals and 29 nuclei from one animal deficient in specific pairing were micrographed in the electron microscope. The total lateral component (LC) length was only determined for the best preserved complements ( 87 normal and 16 aberrant nuclei) in which most or all LCs could be unambigously traced. In the remaining nuclei, in which insufficient spreading and/or the position of the nucleolus prevented complete tracing of the LCs, the degree of SC formation was estimated subjectively and the frequencies of chromosome associations counted. 


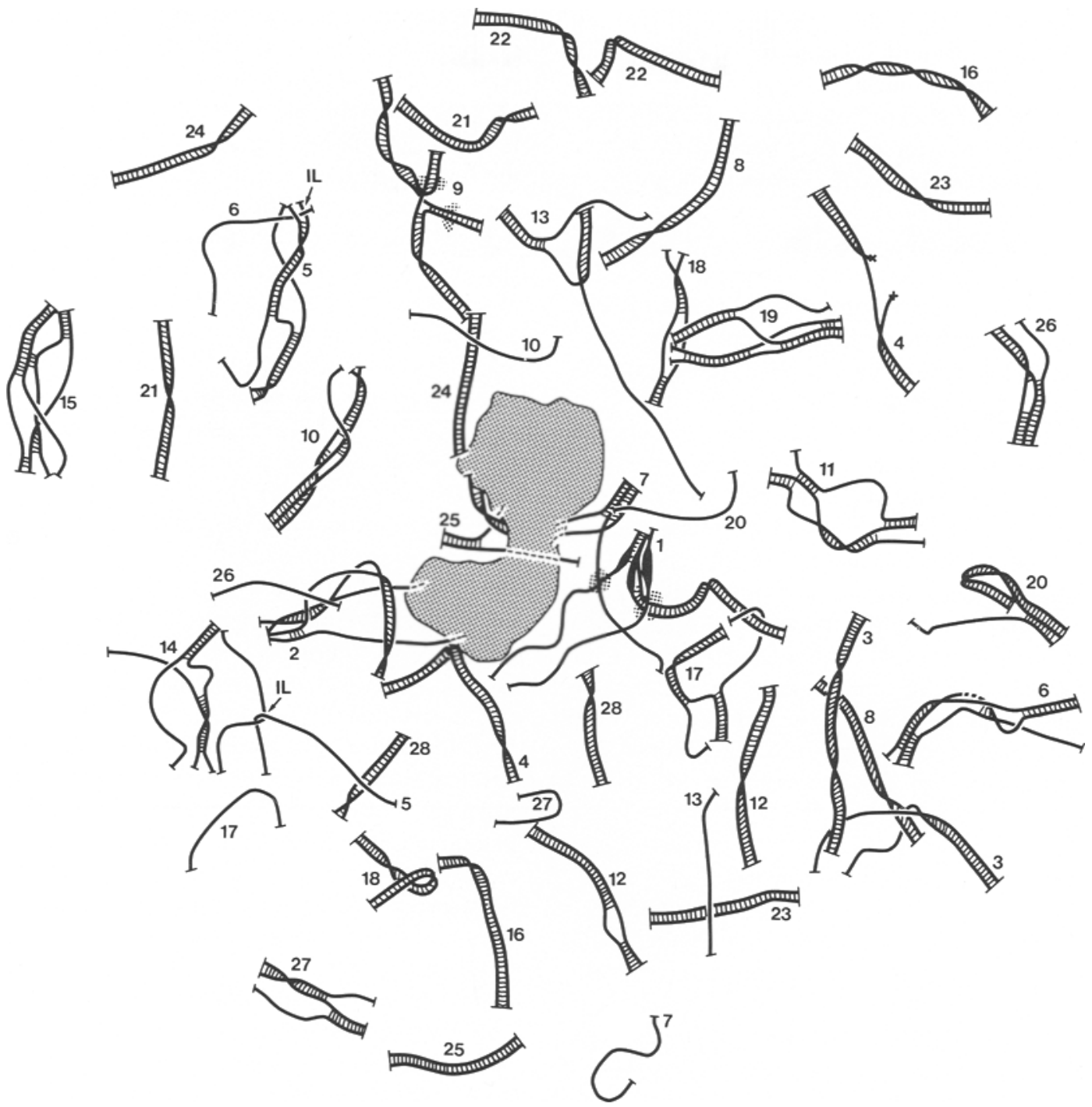

Figure 1. A micrograph and a tracing of a spread chromosome complement at $67 \%$ pairing from animal 1 carrying translocation 1. The complement includes 24 bivalents (numbers 3, 4, 8, 12, 16, 18, 21-25, 28), 9 univalents and 9 trivalents (numbers $5-7,10-11,13,17,20,26-27), 6$ quadrivalents $(1,2,9,14,15,19)$ and an association of 3 chromosomes (number 13), including the long translocation chromosome T1. The individual chromosome sets are numbered from 1 to 28 based on decreasing mean LC length of the four homologues making up either a quadrivalent, a trivalent and a univalent or two bivalents of similar length.

One of the trivalents, possibly chromosomes number 11 , the univalent number 13 and the short univalent number 27 may together with the association of 3 chromosomes (number 13) comprise the two chromosome sets affected by the translocation. Knobs are denoted by hatching. Arrows indicate subtelomeric associations not involving the $\mathrm{SC}$. $\mathrm{IL}=$ interlocking. $(\mathrm{Bar}=5 \mu \mathrm{m})$. 


\section{RESULTS}

\subsection{The temporal sequence of zygotene and pachytene nuclei}

The spread chromosome complements were divided into three stages on the basis of the extent of SC formation. The zygotene stage (35 nuclei) included nuclei in which less than $95 \%$ of the lateral components were combined into SCs. The zygotene-pachytene transition (33 nuclei) contained nuclei from 95 to 99 percent paired and the pachytene stage (45 nuclei) completely paired nuclei and nuclei with neglible asynapsis at the sites of pairing partner exchanges.

As can be seen from Table I the mean length of one genome was nearly the same at the three stages. The table also shows that the LC length of the genome for tetraploid spermatocytes was about the same as that previously reported for diploid spermatocytes at corresponding stages whether determined from spread (35) or sectioned nuclei (16). This is in contrast to the situation in the female (Table I) where an increase in ploidy level is accompanied by a decrease in the LC length of the genome. The significance of this difference is unknown.

\subsection{Zygotene (66-95\% pairing)}

\subsubsection{Synapsis and SC formation}

Due to the small number of tetraploid males obtained after the cold treatment and the difficulty in preserving chromosome complements at early zygotene (35) the earliest zygotene nuclei adequately spread and stained had $66 \%$ of the LCs paired into SCs.

Table II shows the LC lengths per genome, the mean percentage of pairing and the frequency of chromosome configurations of the 35 spread nuclei from the three animals. It can be seen from the table that there were only minor differences among the three animals, the most interesting being the higher frequency of bivalents and lower frequency of quadrivalents in animal 3 , in which the mean percent pairing is about $10 \%$ higher than in animals 1 and 2 . The mean number of chromosome associations in all nuclei and their range and standard deviation were large as expected for events occurring by chance.

Assuming that the four homologues of each of the 28 chromosomes in a tetraploid spermatocyte are so located that pairing and SC formation occur with equal probability between any two LCs at either end, the probability of simultaneous initiation of SC formation at both ends of the same pair of LCs is 0.33 . Formation of a quadrivalent requires initiation of SC formation between different combinations of LCs at opposite ends which has a probability of 0.67 (43). With these assumptions, $67 \%$ of the 28 chromosome quartets will pair as quadrivalents (18.7) and $33 \%$ as pairs of bivalents ( 18.7 bivalents). In three nuclei, this was actually observed. Seven nuclei had 15,16 or 17 quadrivalents while the remaining 25 nuclei contained between 7 and 14 quadrivalents (Figure 6).

A survey micrograph of a nucleus at $67 \%$ pairing is shown in Figure 1. The nucleus contained 9 univalents, 24 bivalents, 9 trivalents, 7 quadrivalents and one association of three chromosomes. The chromosome complement of a second nucleus at the same stage of pairing (66\%) included 4 univalents, 18 bivalents, 4 trivalents and 15 quadrivalents. The number of trivalents and univalents in the remaining zygotene nuclei with 75 to $95 \%$ of the LCs paired, ranged between 0 and 2 and the number of univalents between 0 and 5 with mean values per nucleus of 0.7 and 1.0, respectively. In more advanced nuclei there was thus a marked reduction in the number of univalents and trivalents indicating that unpaired univalents are capable of finding and recognizing their homologues at late zygotene, yielding associations of the four homologues in the form of a quadrivalent or two bivalents.

Except for chromosomes 1 which carry a large knob (chromosomes 1, Figure 1), chromosomes 2 carrying the nucleolus organizer regions (chromosomes 2, Figure 1) and a quartet of shorter chromosomes (usually ranking as number 9-10 by length) identifiable by a small knob (chromosomes 9 , Figure 1) it was not possible to identify individual chromosomes by criteria other than their LC length. Based on this criterion, it was apparent that all chromosome associations (except those involved in the chromosomal rearrangements, see section 3.5) found in zygotene nuclei involved only homologous chromosomes. This shows that synapsis and SC forma- 
tion, even when four copies of each chromosome of the genome are present as in an autotetraploid, operates with a high degree of specificity, which is unaffected by the competition between pairing partners in the presence of more than two copies of each chromosome.

Several incompletely paired trivalents and quadrivalents (denoted by arrows in the micrograph in Figure 1) revealed subtelomeric associations between apparently homologous chromosomes in which SC formation was not yet initiated. These associations and the short SC segments $(0-2.5 \mu \mathrm{m})$ extending from the attachment plaques of LCs in many incompletely paired trivalents and quadrivalents (Figures 1 and 3 ) provide additional indications for the involvement of subtelomeric chromosome regions in the initial recognition between homologous chromosomes. It is furthermore evident that each chromosome has the capacity of associating with a homologue at either side of the chromosome (see for example chromosomes 10 and 20 in Figure 1).

An unexpected complication of this analysis was the presence of a chromosomal rearrangement in two of the investigated animals, involving two nonhomologous chromosomes in each of the animals (see section 3.5). In Figure 1, one of the associations of three chromosomes (number 13, LC lengths 5.1, 5.6 and $9.5 \mu \mathrm{m}$ ) probably included two homologues and a long rearranged chromosome. Due to the incomplete pairing, the remainder of the chromosomes belonging to the affected chromosome sets could not be identified in this and in several other mid-late zygotene nuclei (Table II).

The vast majority of quadrivalents (more than 90\%) contained only one pairing partner exchange as expected if initiation of SC formation is limited to one site at each end of the chromosome. In only a few cases were SC segments found which did not extend from a subterminal site of the homologues (quadrivalent 15 in Figure 1 and quadrivalent 3 in Figure 3). It is considered unlikely that these few interstitial SC segments reflect the activity of true interstitial recognition sites. They may have arisen as the result of fortuitous SC formation between LCs brought into proximity either by interlocking or after the association of the four homologues at
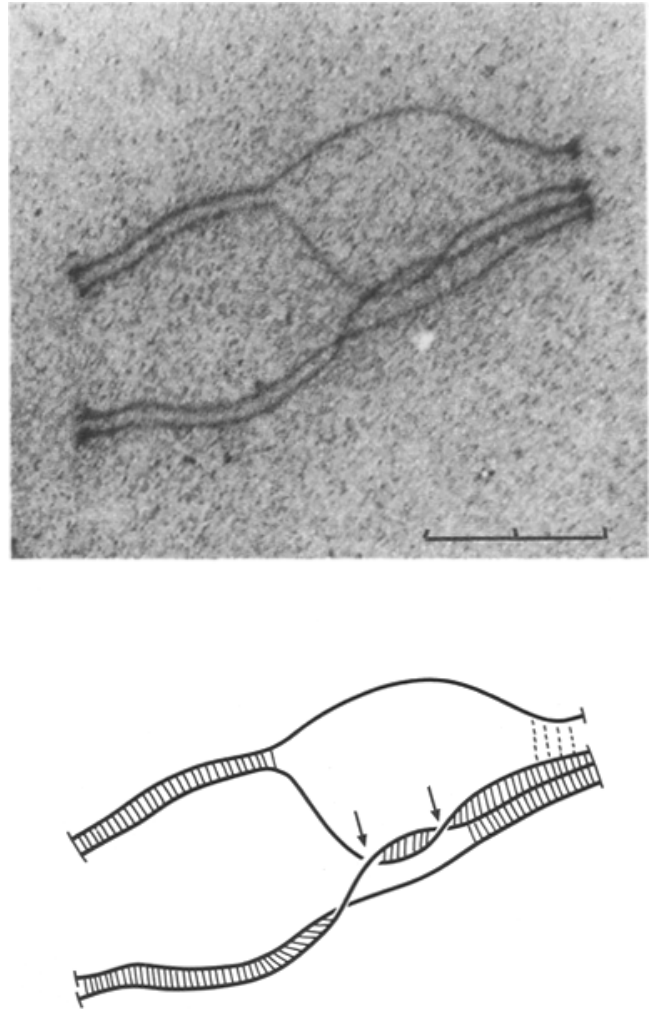

Figure 2. A quadrivalent in which two of the four homologues are intertwined (denoted by arrows). Completion of SC formation in this quadrivalent may result in either two interlocked bivalents or more likely in a quadrivalent with two pairing partner exchanges, the interstitial SC formation being initiated between the intertwined LCs. $(B a r=2 \mu \mathrm{m})$.

subterminal sites.

The high frequency of quadrivalents at zygotene, in some nuclei approaching the theoretical maximum of $67 \%$, implies that association of the four members of each chromosome quartet occurs in a large proportion of the chromosome sets prior to and during SC formation at zygotene.

\subsubsection{Interlocking}

A total of 42 chromosome and bivalent interlockings were found in the 35 zygotene comple- 


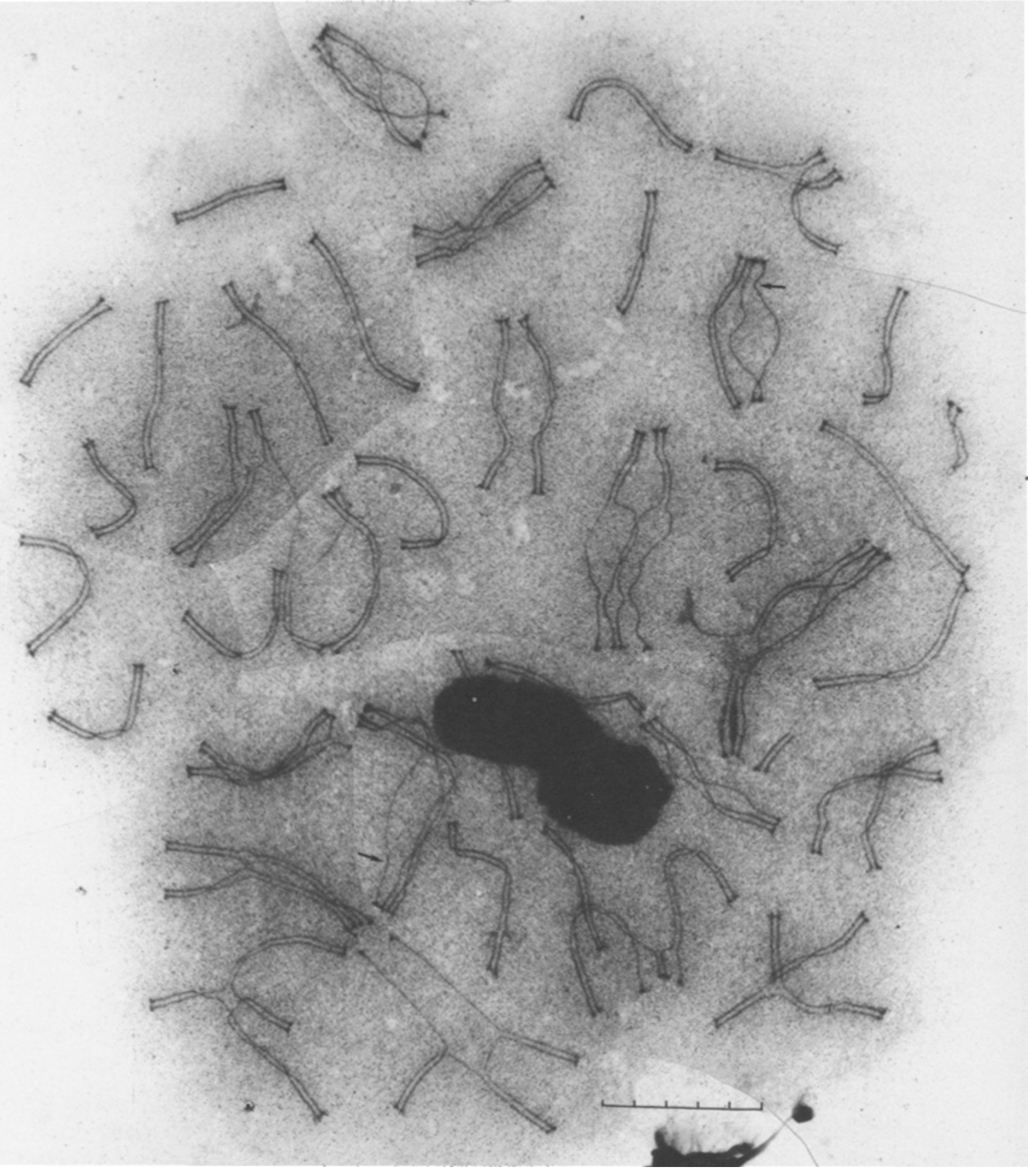

ments analysed. In addition, intertwinings such as that shown in Figure 2, were identified in several cases. The topological relationship of overlapping LCs in quadrivalents could not be equivocally resolved in most cases due to the near parallel orientation of the individual homologues of a chromosome quartet, and it was uncertain to what extent intertwining and interlocking of homologues in quadrivalents contributed to the pairing pattern observed at zygotene. Since interlocked chromosomes of a quadrivalent are homologous the juxtaposition of interstitial LC regions by interlocking or intertwining may result in initiation of intersti- 


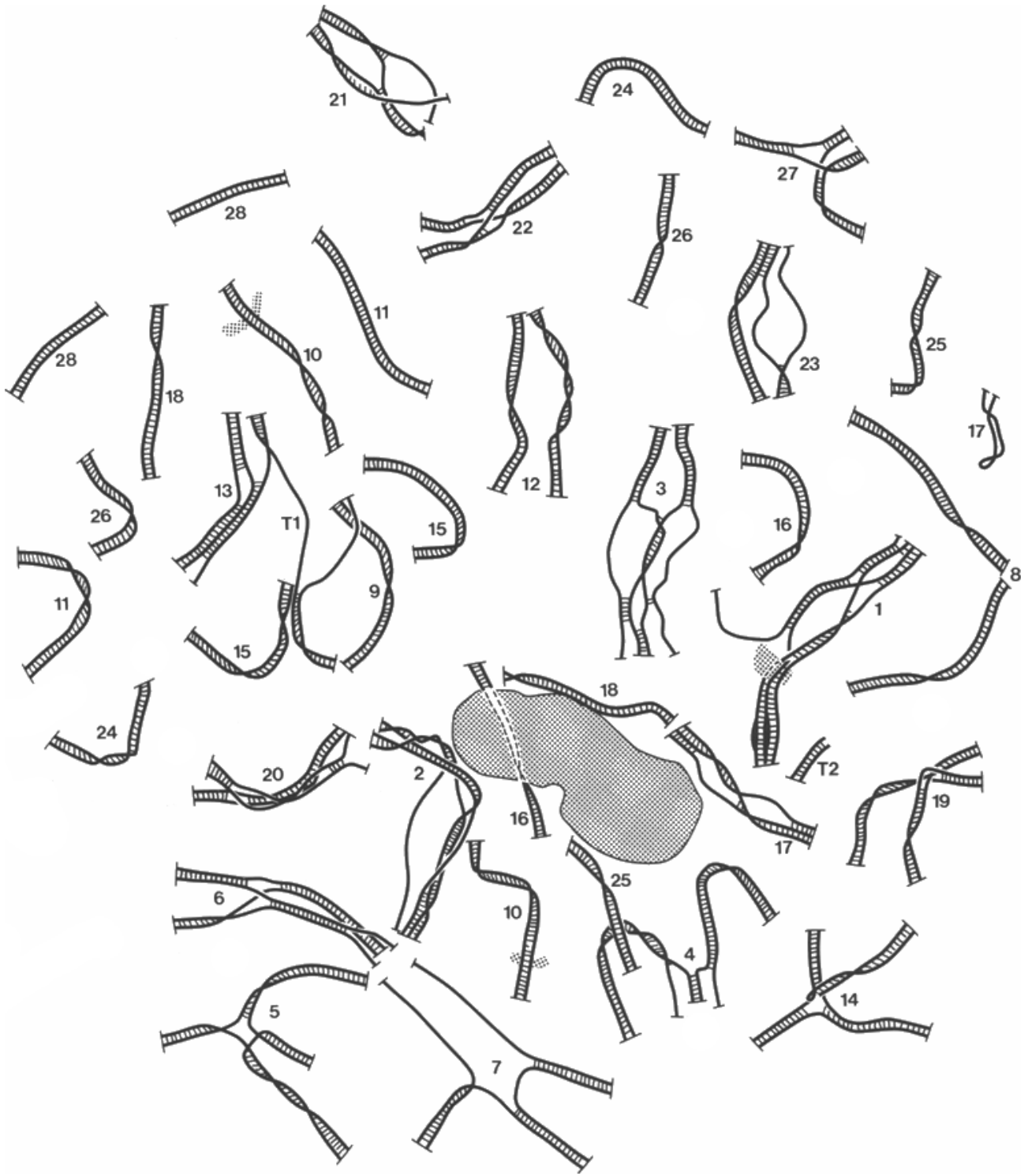

Figure 3. Micrograph and tracing of a spread chromosome complement from animal 1 at $86 \%$ pairing. The complement includes 22 bivalents $(8,10,11,12,15,16,18,24-26,28)$, 1 trivalent and 1 univalent (17), 13 quadrivalents $(1-7,14,19,20,22,23,27)$ an association of 7 chromosomes and a short bivalent fragment $(9,13$, $\mathrm{T} 1, \mathrm{~T} 2$ ), the latter 8 chromosomes comprising the two chromosome sets affected by the translocation. The chromosomes are ranked as described in the legend to Figure 1. Note that two pairs of bivalents (numbers 8,12 ) appear to be associated but at a distance exceeding the width of the SC. The knobs are denoted by hatching. Arrows indicate subtelomeric associations not involving the $\mathrm{SC}$. $(\mathrm{Bar}=5 \mu \mathrm{m})$.

tial SC formation between the interlocked regions rather than triggering the resolution of the interlocking. This will lead to a quadrivalent with two exchanges of pairing partner if the LCs are combined differently outside the interlocked region. 


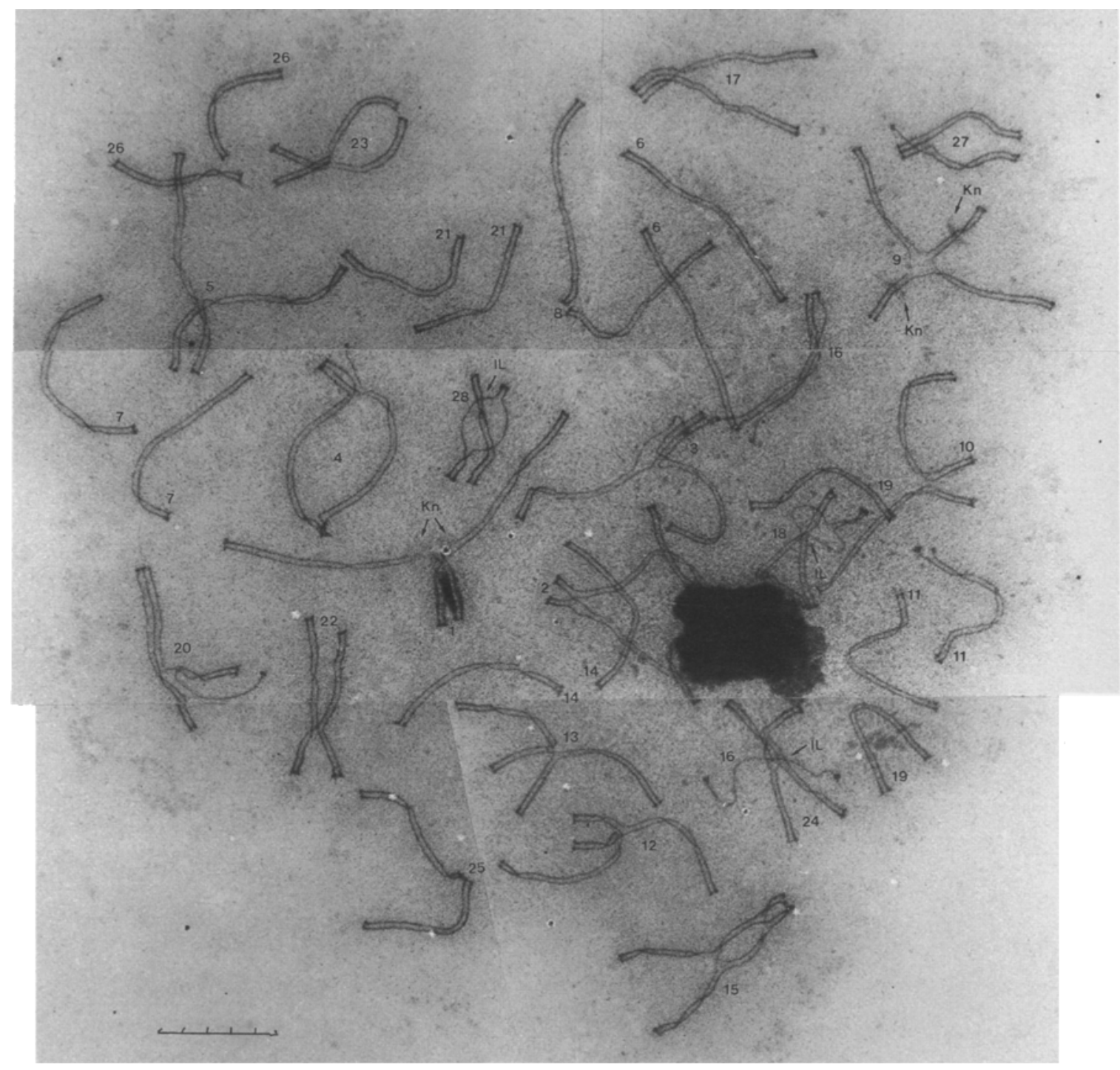

Figure 4. Micrograph of a spread chromosome complement from animal 1 at $95 \%$ pairing. The complement includes 22 bivalents (numbers $6-8,10,11,14,19,21,25-26,28$ ), a trivalent and a univalent (number 16) and 16 quadrivalents $(1-5,9,12-13,15,17-18,20,22-24,27)$. The translocation could not be identified in this nucleus. The univalent belonging to chromosome set 16 is interlocked by the homologues of quadrivalent 24 . Note that the presumed homologous bivalents 8,10 and 25 are associated distally or subterminally. The chromosomes are ranked as described in the legend to Figure $1 . \mathrm{Kn}=$ knob. $\mathrm{IL}=$ interlocking. $(\mathrm{Bar}=5 \mu \mathrm{m})$.

The consequence of interlocking of an unpaired chromosome by a bivalent belonging to a different chromosome set is illustrated in Figure 4 where the univalent chromosome 16 is trapped between the homologous chromosomes
24. The remaining three chromosomes 16 are paired into a trivalent. It is possible that the interlocking will resolve and the released univalent join its homologous trivalent, but it appears more likely that the trapping of a univalent at a 
Table III. Mean number of chromosome associations in tetraploid Bombyx spermatocytes at $95-99 \%$ pairing.

\begin{tabular}{|c|c|c|c|c|c|c|c|c|}
\hline & $\begin{array}{l}\text { Number } \\
\text { of } \\
\text { nuclei }\end{array}$ & $\begin{array}{l}\text { LC length } \\
\text { of one } \\
\text { genome } \\
(\mu \mathrm{m})\end{array}$ & $\begin{array}{l}\text { Percent } \\
\text { pairing }\end{array}$ & $\begin{array}{l}\text { Uni- } \\
\text { valents }\end{array}$ & $\begin{array}{l}\mathrm{Bi}- \\
\text { valents }\end{array}$ & $\begin{array}{l}\text { Tri- } \\
\text { valents }\end{array}$ & $\begin{array}{l}\text { Quadri- } \\
\text { valents }\end{array}$ & $\begin{array}{l}\text { Other } \\
\text { associ- } \\
\text { ations }\end{array}$ \\
\hline Animal $1^{\prime}$ & $24 / 18$ & & & & & & & \\
\hline Mean & & 180 & 97 & 0.1 & 29.9 & 0 & 11.5 & 0.8 \\
\hline S.D. & & 15 & - & - & 5.6 & - & 2.7 & - \\
\hline Range & & $159-210$ & $95-99$ & $0-2$ & $20-39$ & - & $7-18$ & $0-1$ \\
\hline Animal 3 & 9 & & & & & & & \\
\hline Mean & & 209 & 96 & 0 & 36.9 & 0 & 9.9 & - \\
\hline S.D. & & 14 & - & - & 5.8 & - & 2.9 & - \\
\hline Range & & $194-242$ & $95-98$ & $0-1$ & $26-42$ & - & $7-15$ & - \\
\hline Total & $33 / 27$ & & & & & & & \\
\hline Mean & & 190 & 97 & 0.2 & 31.5 & 0 & 11.1 & - \\
\hline S.D. & & 20 & - & - & 6.3 & - & 2.8 & - \\
\hline Range & & $159-242$ & 95-99 & $0-2$ & $20-42$ & - & $7-18$ & - \\
\hline
\end{tabular}

1) Carries translocation 1. Total complement length could not be accurately determined for 6 nuclei. S.D., standard deviation.

late stage of synapsis will delay its movement to the point where specific recognition and subsequent SC formation are no longer possible.

\subsection{Zygotene-pachytene transition (95-99\% pairing)}

In most of the nuclei, the short unpaired LC stretches were found at the site of pairing partner exchange in quadrivalents and only two nuclei contained two univalents. Trivalents were not observed at this stage. In animal 1 , which carries translocation 1 (see section 3.5) the shorter translocation chromosome was folded back onto itself forming a short hairpin in most nuclei. The remaining seven chromosomes involved in or affected by the translocation frequently exhibited unpaired LC segments. These were not included in the calculation of the pairing percentage.

A comparison of the chromosome complements shown in Figure 1 (67\% pairing), Figure $3(86 \%$ pairing) and Figure 4 (95\% pairing) and the data shown in Tables II and III demonstrate that all univalents present at $67 \%$ pairing are homologously paired into bivalents or have combined with their homologues into quadrivalents by the end of the zygotene stage. The extention of $\mathrm{SC}$ formation in quadrivalents tends to reduce the number of pairing partner exchanges, frequently by formation of stretches of double SC (quadrivalents 3, 4 and 17 in Figure 4).

Primary associations not involving the SC, were found between homologous chromosomes or bivalents in nearly completely paired nuclei (for example bivalents 12 in Figure 3 and bivalents 10 in Figure 4). In both cases the homologous bivalents (as judged by their similar lengths) appeared to be held together at a distance exceeding the width of the SC, the tension created during spreading having bent the bivalent segments on either side of the association sites revealing a subterminal physical connection between the bivalents.

As found for zygotene nuclei, the number of quadrivalents varied considerably among the nuclei (Table III and Figure 6) with one nucleus having 18 quadrivalents. In 3 nuclei 15,16 or 17 quadrivalents were observed and the remaining 29 nuclei had between 7 and 14 quadrivalents.

Interlockings were observed in three nuclei, one in each of two nuclei and three in the third. Only one of the interlockings involved nonhomologous chromosomes while the rest were between homologues. 
S. W. RASMUSSEN: Synapsis in tetraploid Bombyx

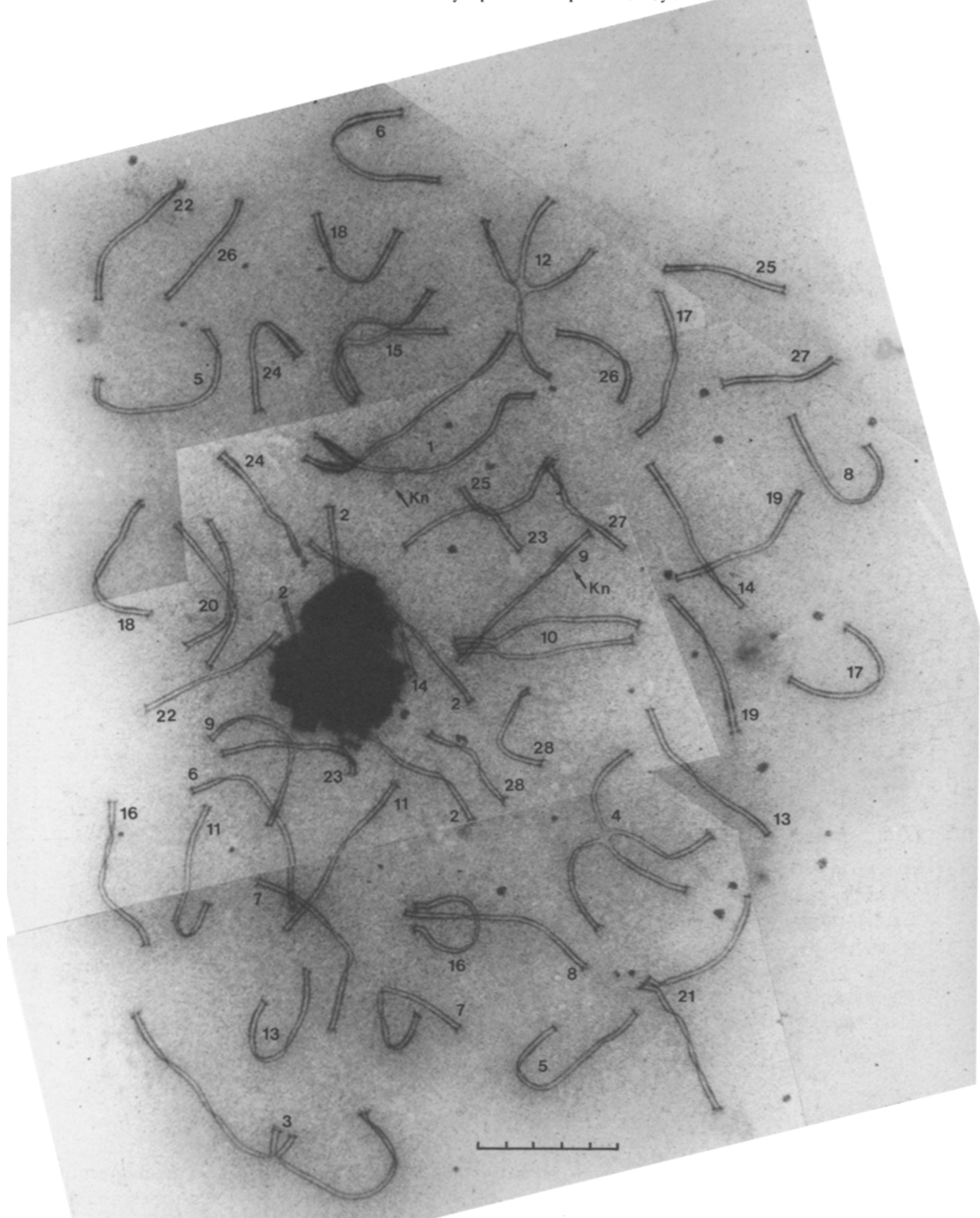

Figure 5. A spread chromosome complement from animal 1 at $100 \%$ pairing. The complement includes 42 bivalents $(1-2,5-9,11,13-14,16-19,22-28)$ and 7 quadrivalents $(3-4,10,12,15,20-21)$. The chromosomes are ranked as described in the legend to Figure $1 . \mathrm{Kn}=$ knob. $(\mathrm{Bar}=5 \mu \mathrm{m})$. 
Table IV. Mean number of chromosome associations in tetraploid Bombyx spermatocytes at 99-100\% pairing.

\begin{tabular}{|c|c|c|c|c|c|c|c|c|}
\hline & $\begin{array}{l}\text { Number } \\
\text { of } \\
\text { nuclei }\end{array}$ & $\begin{array}{l}\text { LC length } \\
\text { of one } \\
\text { genome } \\
(\mu \mathrm{m})\end{array}$ & $\begin{array}{l}\text { Percent } \\
\text { pairing }\end{array}$ & $\begin{array}{l}\text { Uni- } \\
\text { valents }\end{array}$ & $\begin{array}{l}\mathrm{Bi}- \\
\text { valents }\end{array}$ & $\begin{array}{l}\text { Tri- } \\
\text { valents }\end{array}$ & $\begin{array}{l}\text { Quadri- } \\
\text { valents }\end{array}$ & $\begin{array}{l}\text { Other } \\
\text { associ- } \\
\text { ations }\end{array}$ \\
\hline Animal $1^{\prime}$ & $38 / 21$ & & . & & & & & \\
\hline Mean & & 182 & $99-100$ & 0 & 35.5 & 0 & 9.2 & 0.6 \\
\hline S.D. & & 12 & - & - & 4.8 & - & 2.5 & - \\
\hline Range & & $170-212$ & - & - & $24-42$ & - & $5-16$ & $0-1$ \\
\hline Animal 32 & $5 / 4$ & & & & & & & \\
\hline Mean & & 208 & $99-100$ & 0 & 43.6 & 0 & 6.2 & 0 \\
\hline S.D. & & 7 & - & - & 1.0 & - & 1.9 & - \\
\hline Range & & $201-217$ & - & - & $42-50$ & - & $3-8$ & - \\
\hline Animal $5^{3}$ & 2 & & & & & & & \\
\hline Mean & & 183 & $99-100$ & 0 & 48.0 & 0 & 4.5 & 0 \\
\hline Total & $45 / 27$ & & & & & & & \\
\hline Mean & & 186 & $99-100$ & 0 & 37.0 & 0 & 8.7 & - \\
\hline S.D. & & 15 & - & - & 5.8 & - & 2.8 & - \\
\hline Range & & $170-217$ & - & - & $24-52$ & - & $3-16$ & - \\
\hline
\end{tabular}

1) Carries translocation 1. Total complement length could not be accurately determined for 17 nuclei.

2) Carries translocation 2 . Total complement length could not be accurately determined for 1 nucleus.

3) Tetraploid nuclei formed by chromosome doubling in otherwise diploid animal.

S.D., standard deviation.

\subsection{Pachytene (99-100\% pairing)}

Even in apparently completely paired chromosome complements, short regions at the site of pairing partner exchange remained unpaired (quadrivalent 4 and 12 in Figure 4). It is, however, considered unlikely that synapsis in such regions ever progresses to such an extent that the short unpaired LC stretches become fully paired with an SC. Nuclei with up to $1 \%$ unpaired LCs were therefore included in this group. The abundant asynapsis in the association involving the translocations and their homologues were not taken into account in the determination of the pairing percentage stages.

A typical pachytene nucleus is shown in Figure 5. The nucleus contained 42 bivalents and 7 quadrivalents one of which (chromosomes 15) had two exchanges of pairing partner. In quadrivalents 3,10 and 21 the sites of pairing partner exchange was close to the telomeres, possibly indicating that conversion of these quadrivalents was in progress at the time of fixation. In the remaining quadrivalents (numbers $4,12,15,20$ ) the exchange of pairing partner was located approximately in the middle of the multivalent.

It was evident when the spread complements in Figures 1, 3, 4 and 5 were compared, that a considerable modification of the initial synapsis and SC formation had occurred between midlate zygotene and pachytene. The double SCs as well as the multiple exchanges of pairing partner in some early quadrivalents were replaced by normal synapsis and SC formation which, apart from the presence of quadrivalents, appeared as regular as in the diploid.

The data given in Table IV and Figure 6 show that completion of pairing and SC formation was accompanied by a further reduction in the number of quadrivalents from a mean at zygotene of 13.3 to 8.7 at pachytene, only one of the 45 pachytene nuclei having more than 14 quadrivalents. The reduction in the number of quadrivalents was matched by a corresponding increase in the number of bivalents from a mean at zygotene of 25.1 to 37.0 at pachytene (Tables II-IV and Figure 6). A comparison of the frequency of chromosome associations in te- 


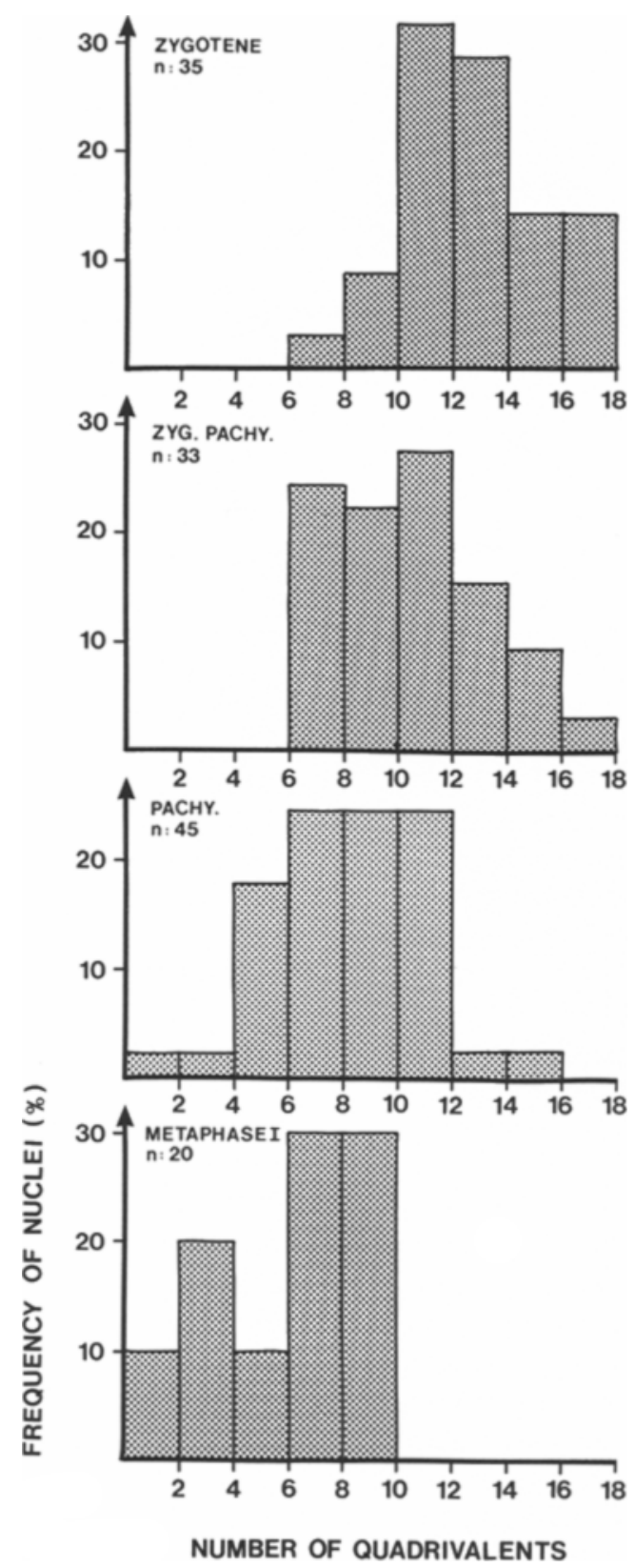

Figure 6. The relative quadrivalent frequency in nuclei at zygotene, the zygotene-pachytene transition, pachytene and metaphase I (data from 18) with 1-2, $3-4,5-6, \ldots$. etc. quadrivalents. $n$ equals the number of nuclei. traploid spermatocytes at metaphase I (18) and at pachytene (Table IV and Figure 6) revealed a further increase in the number of bivalents (from 37.0 to 42.2 ) and a corresponding reduction (from 8.7 to 6.7 ) in the number of quadrivalents. These changes are most likely a consequence of the distribution of crossovers in the quadrivalents at pachytene: in the absence of crossing over and chiasma formation in the two opposite "arms" of the four "arms" of a quadrivalent, elimination of the $\mathrm{SC}$ after pachytene resolves the association of the four homologues comprising a quadrivalent into 2 bivalents. Alternatively, in the presence of only two chiasmata in adjacent "arms" of the cross the result observable at metaphase I is a univalent and a trivalent.

Recombination nodules were not identifiable in spread complements after silver staining and quantitative data on the number and distribution of crossovers in pachytene quadrivalents are thus not available. Examination of two serially sectioned tetraploid nuclei did, however, reveal 50 and 58 recombination nodules in the two mid-late pachytene nuclei. The few quadrivalents in which the distribution of recombination nodules was analysed contained up to three nodules, but the recombination nodules were not distributed among the "arms" in a way which would preserve multivalents after SC elimination. If these nodules represent the total number of crossing over events in these quadrivalents, then all quadrivalents in the two nuclei would convert into two bivalents upon elimination of the SC after pachytene. In agreement with this, exclusive bivalent formation has actually been observed in some cells at metaphase I (18).

Only three interlockings were detected in the 45 nuclei analysed, all involving homologous chromosomes as judged by their similar length, confirming that interlocking of homologous chromosomes is not recognized by the repair system with the same efficiency as when nonhomologous chromosomes are involved, perhaps because the interlocked homologues are not subjected to physical tension during chromosome movements to the same extent as unassociated nonhomologous chromosomes. 


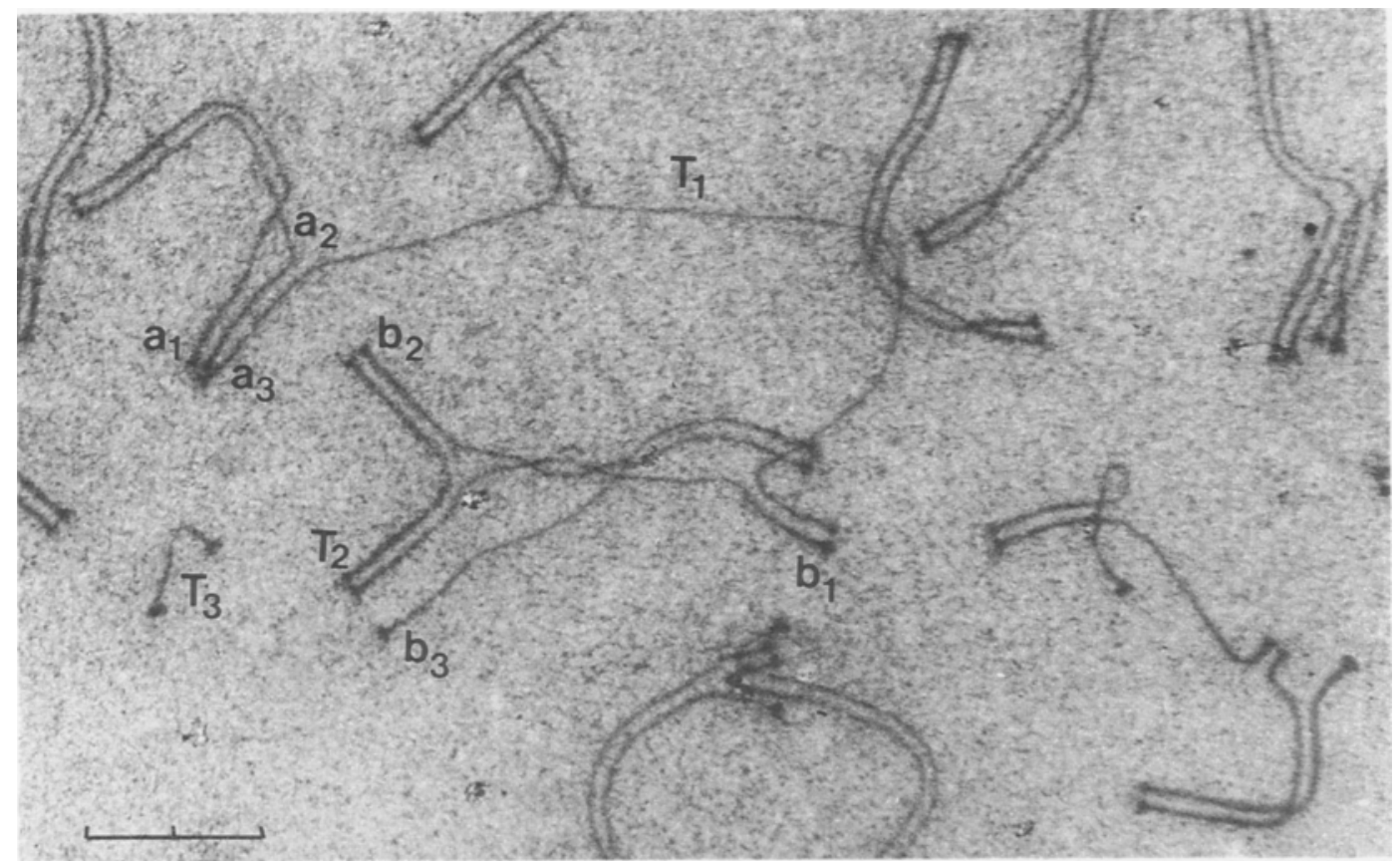

Figure 7. The 8 chromosomes involved in, or affected by the rearrangement in animal $\mathrm{l}$. The longer translocation chromosome ( $\mathrm{T} 1)$ is homologously paired with one chromosome from each of the two chromosome sets $A\left(a_{1}-a_{3}\right)$ and $B\left(b_{1}-b_{3}\right)$. The short translocation chromosome $(T 2)$ is only paired with the longer chromosome set. The relation of the short chromosome T3 to the A and B sets is uncertain. As can be seen in the micrograph, it has distinct telomeric attachment plaques at both ends but does not form an SC with the chromosomes involved in the translocation or their homologues. $(\mathrm{Bar}=2 \mu \mathrm{m})$.

\subsection{Chromosomal rearrangements}

As mentioned in previous sections two of the analysed animals (numbers 1 and 2) contained chromosomal rearrangements, possibly reciprocal translocations.

\subsubsection{Translocation 1}

In animal 1 (Figures 7 and 9) the rearrangement was identified in $62 \%$ of the analysed nuclei and involved two non-homologous chromosomes of nearly equal length (mean lengths for the two sets of homologues involved: $A$ $\left(a_{1}-a_{3}\right)=6.1 \mu \mathrm{m}$ and $\left.B\left(b_{1}-b_{3}\right)=6.3 \mu \mathrm{m}\right)$. The longer translocation chromosome $(\mathrm{T} 1=9.7 \mu \mathrm{m})$ paired with its homologous segments at either end, giving rise to an association of 5 or 7 chromosomes.

The pairing behaviour of the smaller translo- cation chromosome $(\mathrm{T} 2=3.6 \mu \mathrm{m})$ was less regular: in two of the 27 analysed zygotene and zygotene-pachytene nuclei in which a translocation multivalent was identified, the shorter translocation chromosome was absent. The T2 chromosome was present as a foldback paired univalent in 11 nuclei. In the remaining 14 nuclei, $\mathrm{T} 2$, in most cases foldback paired with itself, had formed a second SC segment with a chromosome B. With one exception, both telomeres of $\mathrm{T} 2 \mathrm{had}$ distinct telomeric plaques indicating that both ends of this chromosome were attached to the nuclear envelope. The extent of SC formation between $\mathrm{T} 2$ and its presumed homologous segments on the chromosomes B never exceeded half of the length of $\mathrm{T} 2$, possibly indicating that the foldback pairing preceded SC formation with a chromosome B. In four nuclei the T2 chromosome had a short 

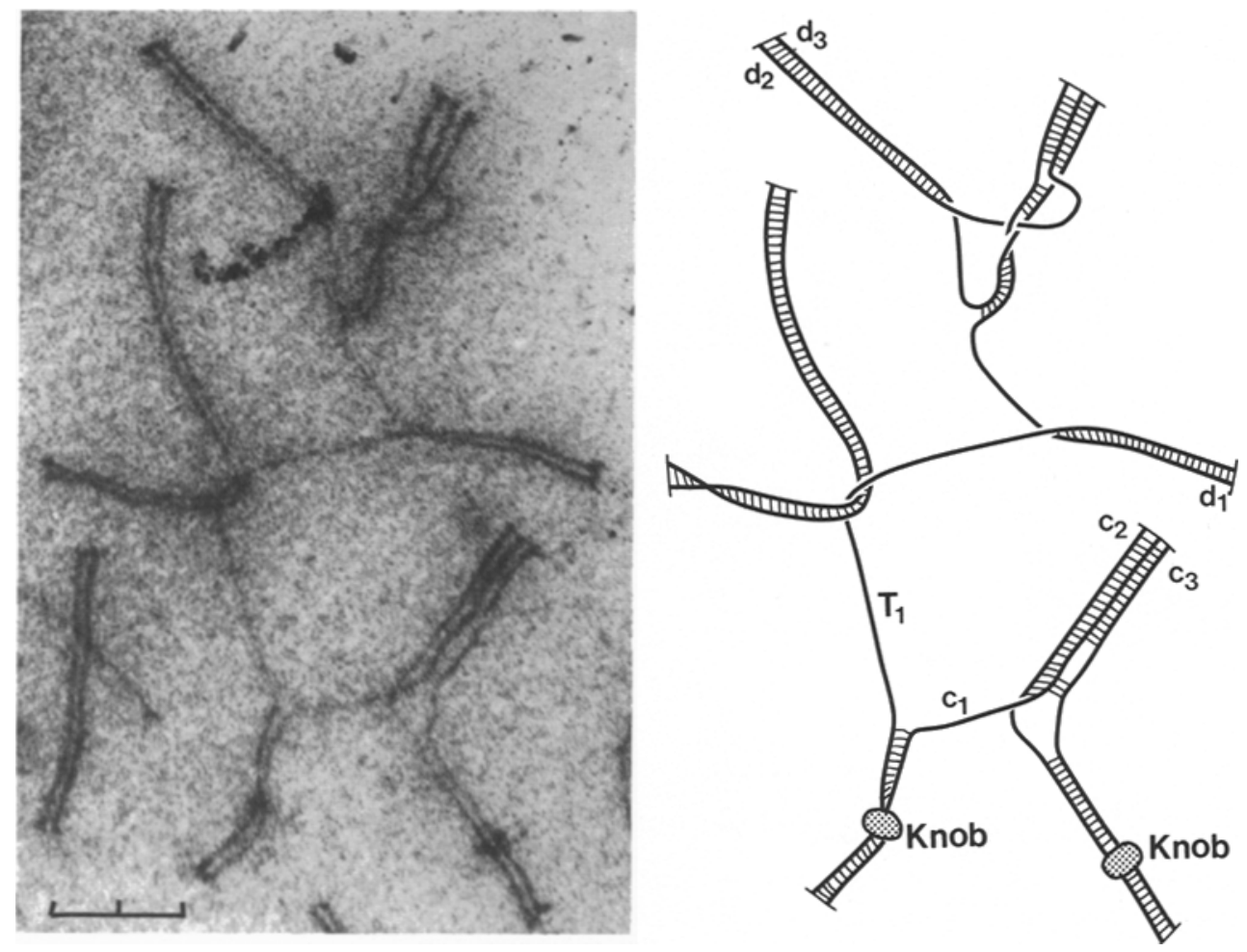

Figure 8. Association of 7 chromosomes involved in or affected by the translocation in animal 2. The translocation has accurted between one of the shorter knob bearing chromosomes $C\left(c_{1}-c_{3}\right)$, ranking as numbers $9-10$ by length and a slightly longer chromosome set $D\left(d_{1}-d_{3}\right)$. The long translocation chromosome (T1) is paired with an SC segment to its respective homologous segments on chromosomes $C$ and $D$. The second translocation chromosome was not identified in this nucleus. $(\mathrm{Bar}=2 \mu \mathrm{m})$.

discontinuity of the LC at the tip of the hairpin. This, most likely reflects a secondary breakage of the LC, although it cannot be entirely excluded that LC fusion between two monotelomeric fragments accounts for the continuous T2 chromosome present in the remaining 21 nuclei. Pairing between $\mathrm{T} 2$ and a chromosome $\mathrm{A}$ was never observed.

Based on the similarity of the combined length of $T 1$ and $T 2(13.3 \mu \mathrm{m})$ and the sum of the mean lengths of the chromosomes $\mathrm{A}$ and $\mathrm{B}$ $(12.4 \mu \mathrm{m}), \mathrm{T} 1$ and $\mathrm{T} 2$ most likely arose by a reciprocal translocation between a chromosome $A$ and a chromosome B (Figure 9). The fact that $\mathrm{T} 2$ never forms a SC with members of the $A$ set is explicable if the break point is located distal to the subterminal recognition site on the A chro- mosome and $\mathrm{T} 2$ hence lacks a recognition site for A.

In addition to $T 1$ and $T 2$, expected as the result of a reciprocal translocation, a third short chromosome or chromosome fragment, T3 (mean length $1.6 \mu \mathrm{m}$ ) was present in 22 of the 27 nuclei in which the rearrangement was identified. The short T3 had distinct telomeric attachment plaques at both ends (Figure 7) and was foldback paired into a short hairpin in nearly all nuclei. Two nuclei contained 2 copies of T3 which either formed a short "bivalent" or one T3 was paired with one of the chromosomes $A$ and the other formed a hairpin. Pairing between T3 and one of the chromosomes $\mathrm{A}$ was observed in an additional 7 nuclei while $\mathrm{T} 3$ was present as a univalent in the rest. 


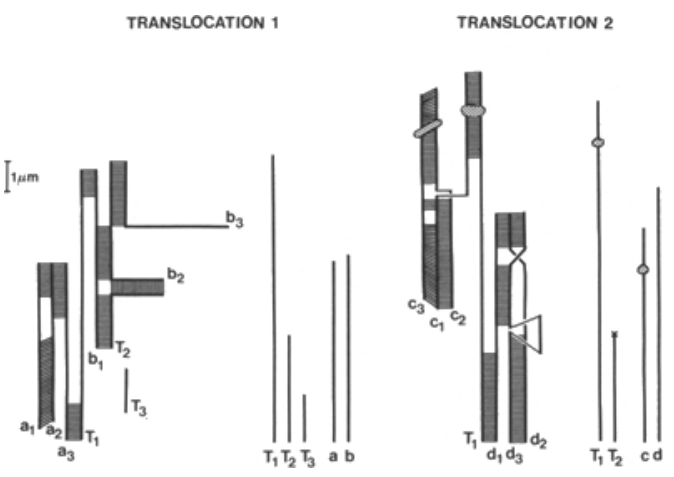

Figure 9. Schematic drawing of the pairing pattern in the translocations shown in Figures 7 and 8 accompanied by an idiogram giving the mean length of the chromosomes involved. The $\mathrm{T} 2$ chromosome in translocation 2 was only observed in a single nucleus. Only the thick lines indicate actual LC length. Hatched areas denote the position of the knobs in translocation 2 . Due to the varying extent of SC formation between the longer translocation chromosomes (T1) and their homologous segments in different nuclei, the position of the break points in the $\mathrm{T} 1$ chromosomes could not be identified.

The origin of the short T3 chromosome is uncertain; according to its pairing behaviour it appears to be homologous to the chromosomes A although SC formation was only observed in 7 of the 27 nuclei. If this is the case, the rearrangement cannot be accounted for by a simple translocation but may have involved a more complex rearrangement with subsequent organization of new telomeric attachment plaques at the broken ends of $\mathrm{T} 2$ and $\mathrm{T} 3$.

\subsubsection{Translocation 2}

The second translocation found in animal 2 involved one member of the shorter knob bearing chromosomes $\mathrm{C}\left(\mathrm{c}_{1}-\mathrm{c}_{3}\right)$ and one member of the slightly longer chromosomes $D\left(d_{1}-d_{3}\right)$ (mean lengths $7.2 \mu \mathrm{m}$ and $8.6 \mu \mathrm{m}$, respectively) (Figure 8). The longer translocation chromosome $\mathrm{Tl}$ (mean length $11.5 \mu \mathrm{m}$ ) joined the chromosomes $\mathrm{C}$ and $\mathrm{D}$ into an association of 5 or 7 chromosomes in 10 of the 12 zygotene nuclei traced. In one nucleus, a presumed sec- ond translocation chromosome, $\mathrm{T} 2$, was identified, paired throughout its entire length with a chromosome D. A distinct telomeric attachment plaque was present at one end while the LC at the other end lacked this terminal differentiation. The combined length of the T1 and the T2 chromosomes $(15.1 \mu \mathrm{m})$ was nearly the same as the sum of the mean lengths of the chromosomes $\mathrm{C}$ and $\mathrm{D}(15.8 \mu \mathrm{m})$ indicating that $\mathrm{T} 2$ actually represents the second product of a reciprocal translocation (Figure 9).

\subsection{Partial failure of recognition between homologues}

The initial specific association of homologous chromosomes during the first part of zygotene, the subsequent $\mathrm{SC}$ formation and the correction of the initial pairing through turnover of the central region of the SC in tetraploid Bombyx spermatocytes result in a highly regular synapsis favouring bivalent formation, the relatively few quadrivalents with one or rarely two exchanges of pairing partner being the only disorder introduced by the presence of four instead of two copies of each chromosome.

The chromosomal pairing behaviour of one animal differed markedly from the regular pairing pattern described above and found in the rest of the animals analysed. In this aberrant animal, the progression of pairing and SC formation were arrested at about $50 \%$ pairing. Completely paired complements were not found. The mean LC length of one genome amounted to $229 \mu \mathrm{m}$, i.e., approximately the same as in nuclei with normal pairing $(187 \mu \mathrm{m})$, whereas a comparison of idiograms from normal and the aberrant animal revealed marked differences in LC length of several chromosomes, one or more LCs from the aberrant animal being almost twice as long as the normal chromosomes 1 and 2 . In addition nearly all complements contained several circular chromosome fragments (Figures $11 \mathrm{a}, \mathrm{b}$ and Table $\mathrm{V}$ ) indicative of uncontrolled breakage/reunion events. Apart from these irregularities, the morphology of the SCs and the unpaired LCs appeared normal (Figures 11 a and 12).

The LC length of one genome, the percent pairing, the total number of chromosomes and 
Table V. Lateral component length of one genome, percent pairing and number of chromosome associations in 16 nuclei from a Bombyx male with aberrant synapsis.

\begin{tabular}{|c|c|c|c|c|c|c|}
\hline $\begin{array}{l}\text { Nucleus } \\
\text { number }\end{array}$ & $\begin{array}{l}\text { LC length } \\
(\mu \mathrm{m})\end{array}$ & $\begin{array}{l}\text { Percent } \\
\text { pairing }\end{array}$ & $\begin{array}{l}\text { Univa- } \\
\text { lents }\end{array}$ & $\begin{array}{l}\text { Biva- } \\
\text { lents }\end{array}$ & $\begin{array}{l}\text { Fully or partly nonhomologous chromosome as } \\
\text { The number of chromosomes per association } \\
\text { roman numbers. CF, circular fragments. The } \\
\text { LCs and and LC fragments is given in paranth }\end{array}$ & $\begin{array}{l}\text { ssociations. } \\
\text { is given in } \\
\text { number of } \\
\text { hesis. }\end{array}$ \\
\hline$!$ & 187 & 55 & 10 & 6 & $10 \mathrm{II}, 2 \mathrm{III}, 4 \mathrm{IV}, 3 \mathrm{~V}, 2 \mathrm{VI}, 1 \mathrm{VII}, 1 \mathrm{XI}$ & $5 \mathrm{CF}(109)$ \\
\hline 2 & 175 & 59 & 3 & 3 & 5II, 2III, 3IV, IVI, IVIII, 2IX, IXI,1XXX & $8 C F(110)$ \\
\hline 3 & 208 & 45 & 6 & 1 & 9II,2III, 2IV,2V, IVI, 1 VII, 1IX, 1XIX, 1XXI & $3 \mathrm{CF}(112)$ \\
\hline 4 & 279 & 60 & 6 & 8 & 2II, 1III, 3IV, 2V, 2VI, 1XI, 1XIII, 1XXVIII & $8 \mathrm{CF}(113)$ \\
\hline 5 & 250 & 46 & 11 & 3 & $8 \mathrm{II}$, IIII, 4IV, 4V, IVI, IVII, IIX, IXXIV & SCF (118) \\
\hline 6 & 203 & 56 & 10 & 4 & 6II, 5III, 1IV, 3V, IVI, IIX, 1 XI, 1XVIII & $5 C F(108)$ \\
\hline 7 & 275 & $5 !$ & 9 & 2 & $5 \mathrm{II}, 1 \mathrm{IV}, 1 \mathrm{~V}, 2 \mathrm{IX}, 1 \mathrm{LXV}$ & $4 \mathrm{CF}(115)$ \\
\hline 8 & 184 & 67 & 8 & 9 & 4II, 6III, 2IV, 1V, 2VII, 1 VIII, 1X, 1XVI & $6 \mathrm{CF}(113)$ \\
\hline 9 & 248 & 48 & 9 & 6 & $5 \mathrm{II}, 1 \mathrm{III}, 3 \mathrm{IV}, 2 \mathrm{~V}, 1 \mathrm{VII}, 1 \mathrm{X}, 1 \mathrm{XII}, 1 \mathrm{XVI}, 1 \mathrm{XVIII}$ & $6 \mathrm{CF}(119)$ \\
\hline 10 & 266 & 50 & 9 & 5 & III, 4III, 5IV, IVII, IIX, IX, 1XIV, IXXII & $3 \mathrm{CF}(115)$ \\
\hline 11 & 236 & 59 & 14 & 9 & 6II, 4III, 3IV, IV, IVI, IXV, IXX & SCF (114) \\
\hline 12 & 253 & 64 & 7 & 9 & 6II, 2III, IV, IVII, IVIII, IIX, 2XXI & $4 C F(114)$ \\
\hline 13 & 237 & 48 & 11 & 6 & 3II, 6III, 3IV, 1V, 1 VI, 1 VIII, IX, IXII, IXVIII & $6 \mathrm{CF}(118)$ \\
\hline 14 & 215 & 45 & 10 & 6 & 3II, 3III, 4IV, IV, 3VI, IVII, IXII, IXIV & $2 \mathrm{CF}(109)$ \\
\hline 15 & 189 & 46 & 21 & 10 & $4 \mathrm{II}, 2 \mathrm{III}, 3 \mathrm{~V}, 1 \mathrm{VI}, 2 \mathrm{IX}, 1 \mathrm{X}, 1 \mathrm{XI}$ & $5 \mathrm{CF}(115)$ \\
\hline 16 & 252 & 45 & 14 & 2 & 8II, 3III, IIV, 2V, 4VI, IIX, IXXV & $5 C F(115)$ \\
\hline
\end{tabular}

chromosome segments are given in Table V. It is evident from these data that the pairing, except from a small number of regularly paired bivalents (from 1 to 10) was highly irregular. Obviously chromosome associations involving more than four chromosomes must be at least in part nonhomologous, but the vast majority of associations of 2 to 4 chromosomes were also classified as nonhomologous from the large differences in LC length of the chromosomes involved. In one nucleus (number 7, Table V) 65 chromosomes were associated forming a complex chain or network of chromosomes (Figure 10). Only 7 of the $71 \mathrm{SC}$ segments joining the 65 chromosomes did not include a pair of telom- eres (the SC between chromosomes 2-8, 2-16, 5-7, 6-18, 19-50, 27-54, 31-39, Figure 10). Double and triple SCs combining three or four LCs in the same region were found in 10 cases, all except one including a set of telomeres.

The $65 \mathrm{LCs}$ in the tracing and the idiogram were numbered according to decreasing length to assess the homology of the chromosomes joined by SC segments. It is evident that similarity in LC length indicates homology of the chromosomes paired with an SC only in few cases (clearly seen in chromosome associations 28-30-32, 33-35, 20-22). Most of the SC segments join nonhomologous chromosomes (for example chromosome associations 3-33, 1-41,

Figure 10. Tracing of an association involving 65 chromosomes from an animal with aberrant synapsis and SC formation (nucleus 7. Table V). The idiogram gives the LC length of the individual chromosomes, ranked and numbered according to decreasing length. A total of $71 \mathrm{SC}$ segments join the 65 chromosomes. $7 \mathrm{SC}$ segments being interstitially initiated, the rest including a pair of telomeres. It is evident from the idiogram and the tracing that most of the SC segments are between nonhomologous chrcmosomes; in only a few cases does the similarity in length (and consequently in chromosome number) indicate homology of the paired chromosomes.

Even when allowance is made for LC stretching during spreading the longest LCs exceed those found in normal nuclei indicating that chromosomal rearrangements have accompanied the aberrant synapsis in this nucleus. 
S. W. RaSmusSen: Synapsis in tetraploid Bombyx

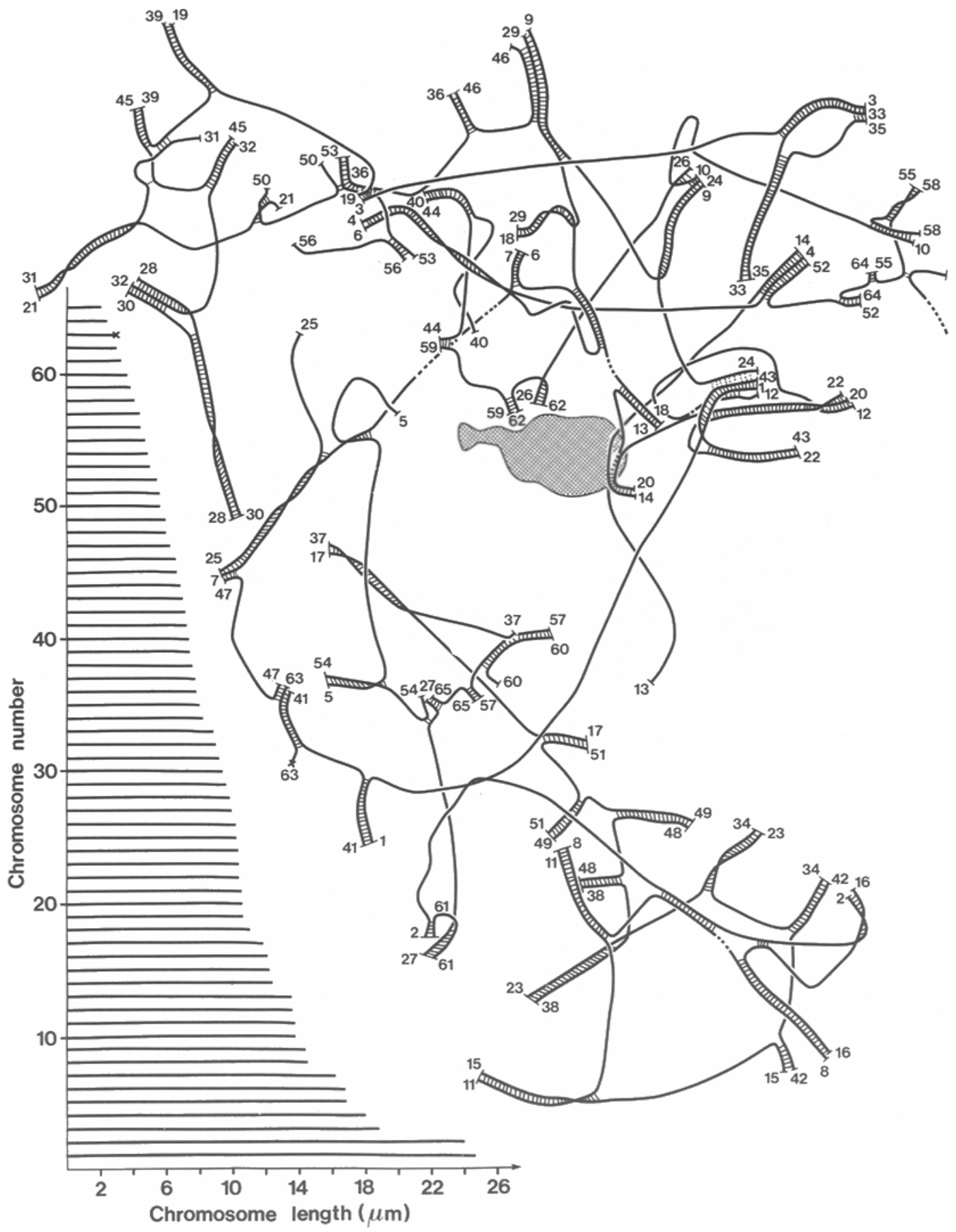




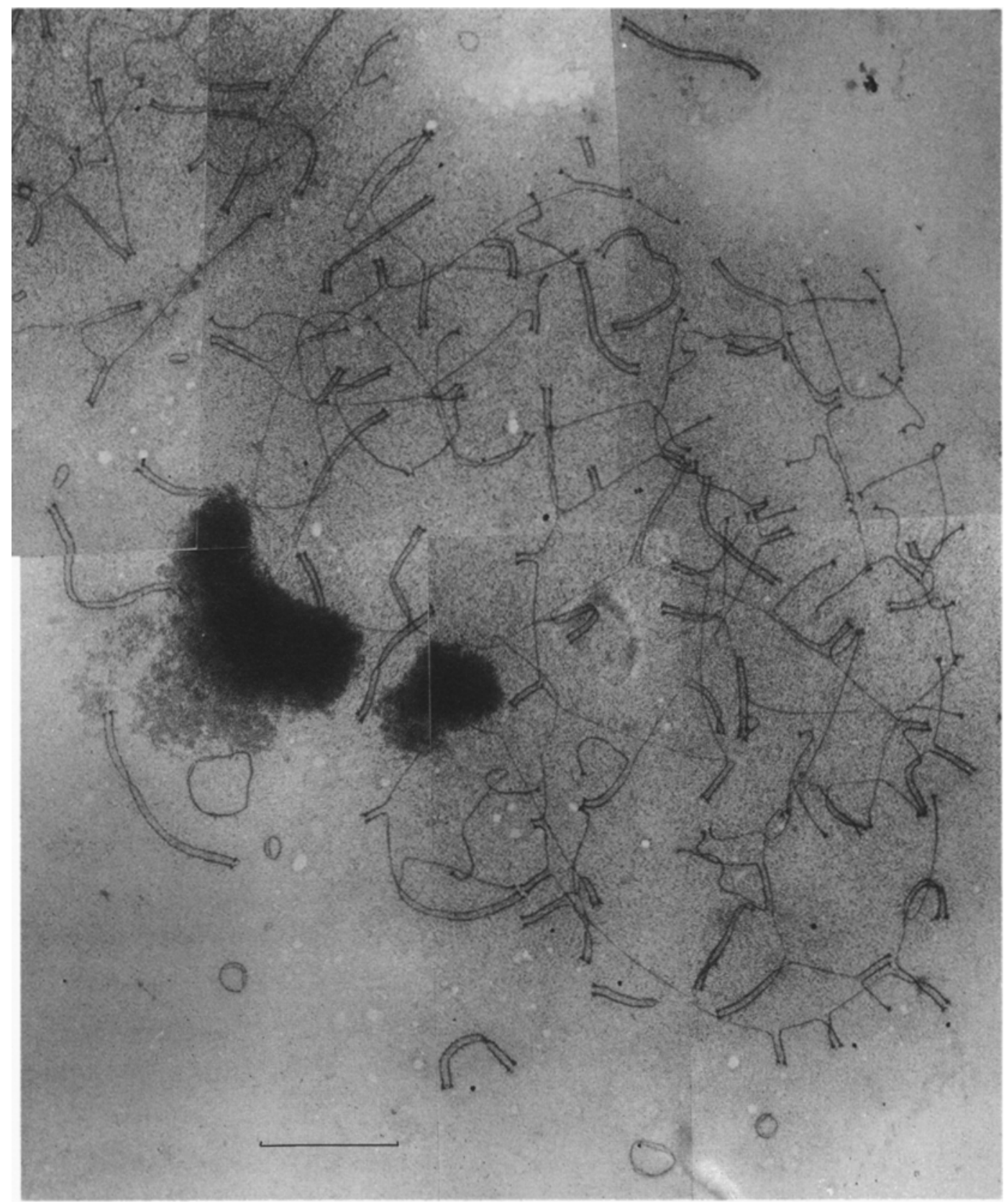

Figure 11. Chromosome complement (nucleus 15, Table V) from an animal with aberrant synapsis and SC formation. Figure $11 \mathrm{a}$, a survey micrograph of the spread complement. (Bar $=5 \mu \mathrm{m}$ ). Figure $11 \mathrm{~b}$, a tracing of the LCs and SCs. Bivalents (b) and univalents (u) are drawn with thin lines, multiple associations ( $m$ ) with thick lines. Figure $1 \mathrm{lc}$, idiogram showing the pairing pattern and the extent of SC formation. Figure 11d, histogram giving the relative distribution of SC segment lengths. The hatched portion of the histogram represents the lengths distribution obtained by excluding the completely paired homologues.

Normal synapsis and SC formation have only occurred between 10 pairs of homologues, while the remaining 


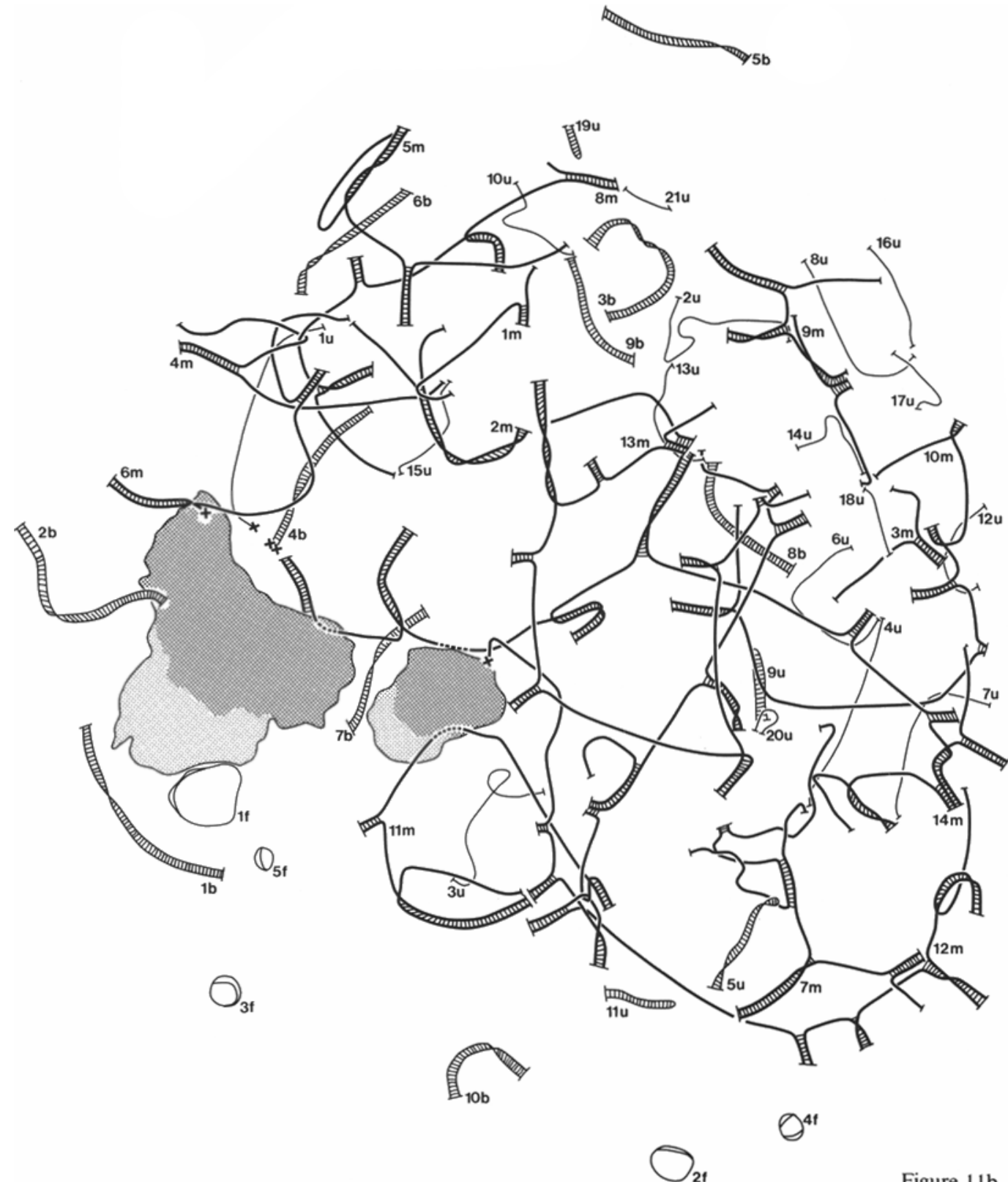

Figure $11 \mathrm{~b}$.

chromosomes are either present as univalents ( 21 chromosomes) or have engaged in various partly or entirely nonhomologous associations.

The majority of the nonhomologous associations consist of chains of chromosomes combined by short SC segments extending $0-2.5 \mu \mathrm{m}$ from the telomeres. Interstitial SC formation is only present in a single case (in association number 7). The prevalence of short distal SC segments is apparently not due to physical hindrance of further progression of SC formation, since free LC segments in most cases extend from the pairing forks, their abrupt bending most likely being introduced by the spreading of the complement. 
S. W. Rasmussen: Synapsis in tetraploid Bombyx
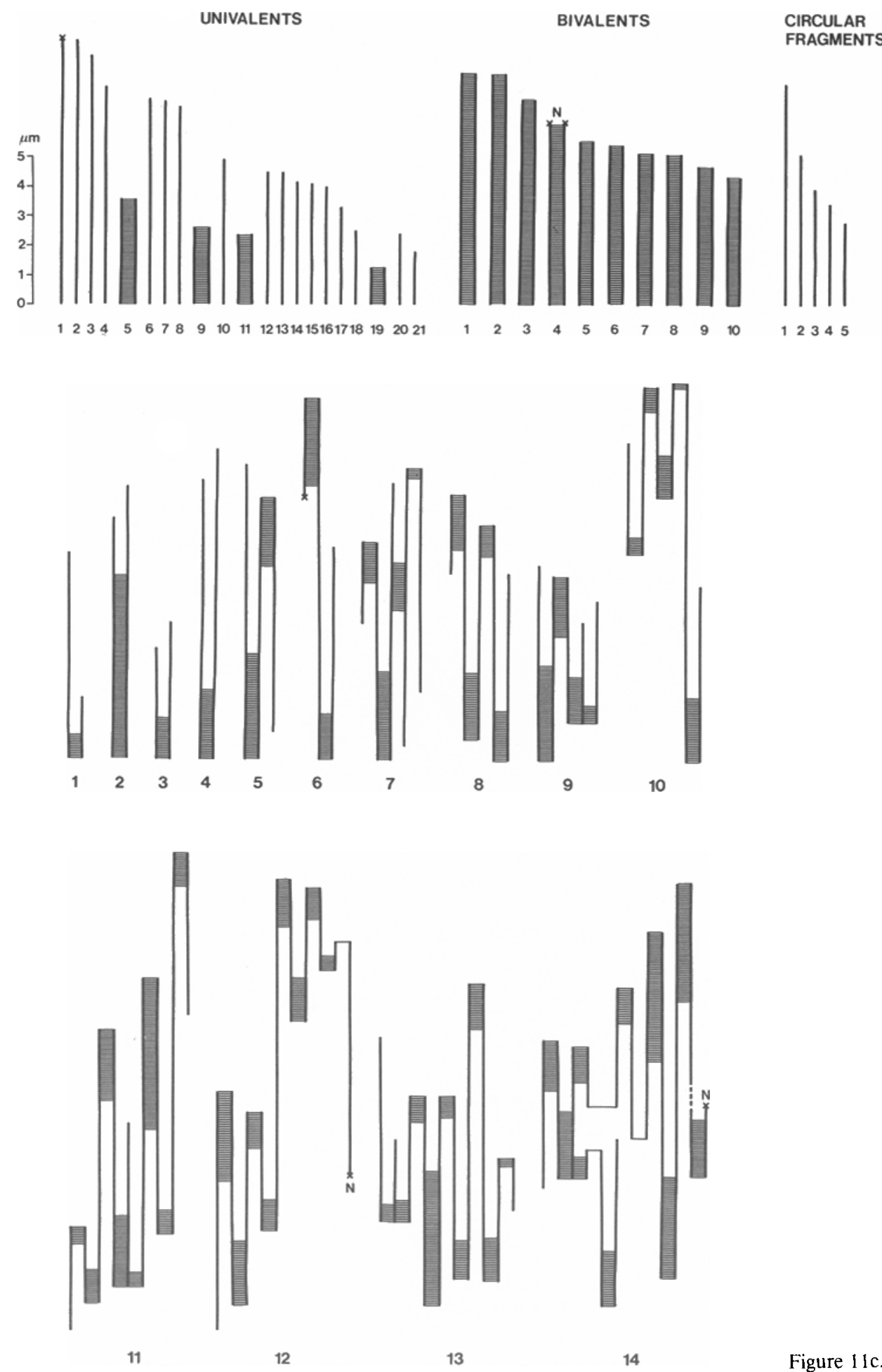

Figure 11c. 


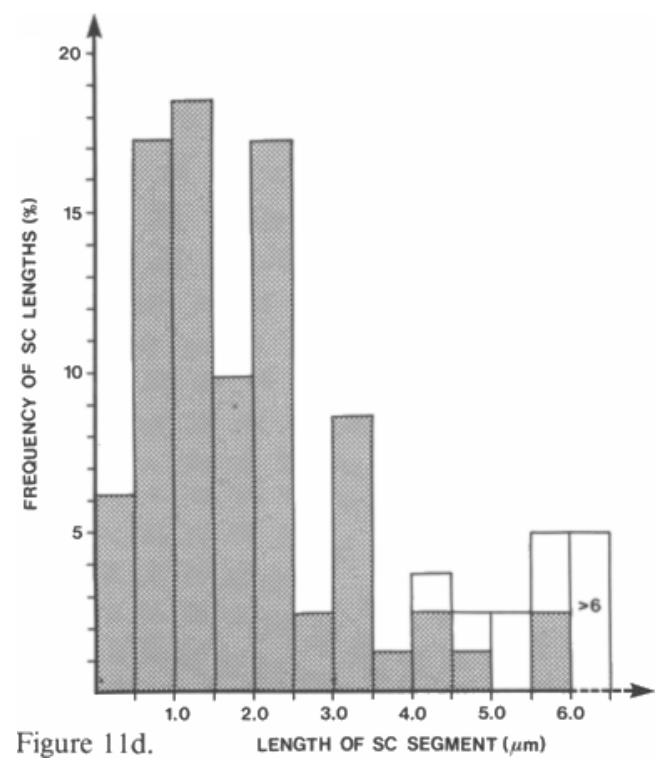

5-54, 9-29-46). In addition to the 65-association the nucleus contained 9 univalents, 2 bivalents, 5 partly or entirely nonhomologous associations of 2-9 chromosomes and 4 circular fragments. The pairing behaviour in this nucleus shows an almost total failure of specific recognition of homologues prior to SC formation.

A survey micrograph of a second nucleus (number 15, Table V) from the same animal is shown in Figure 1la accompanied by a tracing of the LC complement (Figure 11b), an idiogram (Figure $11 \mathrm{c}$ ) and a histogram showing the length distribution of SC segments (Figure 1 Id). The nucleus contained 21 univalents, 10 bivalents, 14 associations involving from 2 to 11 chromosomes and 5 circular fragments. A total of $74 \mathrm{SC}$ segments were present, of which $70 \%$ ranged in length between 0 and $2.5 \mu \mathrm{m}$. If the length of completely paired bivalents are subtracted the prevalence of short SC segments becomes even more pronounced, amounting to $89 \%$. Rather than a continuous spectrum of SC lengths, it thus appears that SC formation in this nucleus was arrested about $2.5-3 \mu \mathrm{m}$ from the telomeres. Although not analysed quantitatively, the impression from the remaining 26 traced nuclei was that this phenomenon was typical of synapsis in this animal.
In a single nucleus (number 2, Table $\mathrm{V}$ ) triple SC formation joined four LCs (Figure 12 and Table VI) in the same region. The 9 associated chromosomes shown in the figure belong to a 30 chromosome association comprising two chains of 19 and 11 chromosomes, joined by a short interstitial SC segment. The LC lengths of the individual chromosomes shown in Table VI demonstrate that the multiple telomeric associations involve both homologous and nonhomologous chromosomes. SC formation involving more than four LCs in the same region was not observed.

\section{DISCUSSION}

\subsection{Alignment of homologous chromosomes}

It has recently been shown that the initial alignment of homologous chromosomes which precedes SC formation in diploid Bombyx spermatocytes is mediated by a short subterminal segment at each end of the chromosome (35). After spreading and silver staining, the subterminal segments of homologous chromosomes were observed to be physically associated, the connection being sufficiently strong to withstand the tension created by the spreading and flattening of the nucleus. In the vast majority of early bivalents the subterminal connections were present only between homologous chromosomes, as judged from their similar lengths. As a rule the subsequent $\mathrm{SC}$ formation begins at the associated subterminal regions and then proceeds to the nearest pair of telomeres. Less frequently, SC formation proceeds in the opposite direction, leaving the short LC segments between the telomeres and the association sites unpaired.

On the basis of these observations it was concluded that the specific pairing of homologous chromosomes with the $\mathrm{SC}$ in diploid Bombyx spermatocytes is the consequence of an initial recognition and specific association of subterminal homologous chromosome regions ("recognition sites") rather than the result of an absolute requirement for homology of chromosome regions to engage in 'SC formation (35). The formation of apparently normal SCs between nonhomologous chromosomes or chromosome segments (see reviews 9 and 48) may 


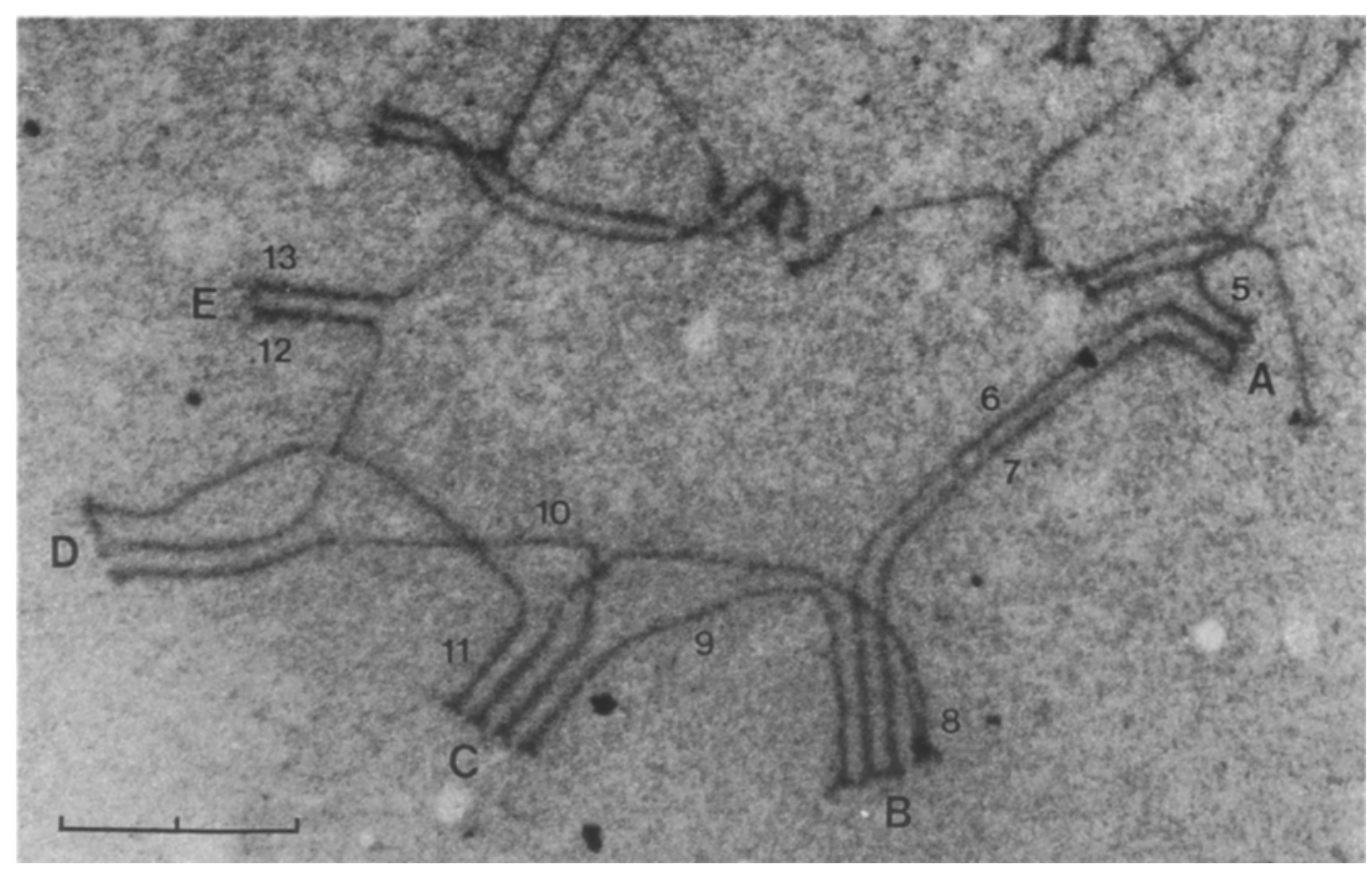

Figure 12. Part of a spread chromosome complement (nucleus 2) from an animal with aberrant synapsis and SC formation. The LC lengths and pairing pattern of all chromosomes included in the 30 -chromosome association to which the 9 chromosomes included in this figure belong are given in Table Vl. The length of each chromosome of the 5 groups of paired telomeres (A-E) in the figure can be read from Table $\mathrm{Vl}, \mathrm{a}_{1}-\mathrm{a}_{3}$ identifying the telomeres of the $A$ group, $b_{1}-b_{4}$ the $B$ group etc.

not signify a loss of the requirement for specificity but may rather indicate that $\mathrm{SC}$ formation per se occurs irrespective of homology of the chromosome segments to be paired as proposed in several recent papers $(13,27,35,46)$.

The observations on chromosome pairing in tetraploid spermatocytes confirm these conclusions. Although early zygotene chromosome complements were not obtained the pairing pattern in quadrivalents at mid zygotene revealed both distant connections (i.e., 2-3 times the width of the $\mathrm{SC}$ ) between homologous chromosomes not yet combined by an SC and a high frequency of short SC segments $(0-2.5 \mu \mathrm{m})$ extending from the telomeres. Some quadrivalents also contained SC stretches initiated subterminally but extending away from the initiation site leaving short distal LC segments unpaired.

The present observations further show that the individual chromosome is capable of recognizing and establishing contact to more that one homologue at a given recognition site; in a number of quadrivalents three or all four chromosomes were associated at one or both ends, implying that the association of two homologous recognition sites or subsequent $\mathrm{SC}$ formation does not exhaust their potential for recognising additional homologues.

Specific pairing with formation of the $\mathrm{SC}$ involving more than two homologues at the same region has been observed in tri- and tetraploid Bombyx oocytes $(34,36)$ as well as in a number of phylogenetically distantly related species such as tetraploid yeast (4), triploid Coprinus (38) and chicken (6), aneuploid human oocytes (44) and bull spermatocytes (8) clearly indicating that this is not a unique feature of meiosis in Bombyx. Reports of triple pairing in plants are less common (see ref. 9). Most likely 
Table VI. Lateral component lengths of the 30-chromosome association to which the chromosomes 5-13 shown in Figure 11 belong. The individual telomeres in groups $A-E$, Figure 11, are denoted $a_{1}-a_{3}, b_{1}-b_{4}, c_{1}-c_{4}, d_{1}-d_{3}$ and $e_{1}-e_{2}$.

\begin{tabular}{llll}
\hline $\begin{array}{l}\text { Chromosome } \\
\text { number }\end{array}$ & $\begin{array}{l}\text { LC length } \\
(\mu \mathrm{m})\end{array}$ & $\begin{array}{l}\text { Chromosome } \\
\text { number }\end{array}$ & $\begin{array}{l}\text { LC length } \\
(\mu \mathrm{m})\end{array}$ \\
1 & 3.9 & 1 & 2.0 \\
2 & 4.3 & 2 & 1.4 \\
3 & 4.8 & 3 & 4.1 \\
4 & $7.7 \quad$ interstitial SC & 4 & 4.1 \\
5 & & 5 & 9.0 \\
6 & $8.4 \mathrm{a}_{1}$ & 6 & 6.2 \\
7 & $5.9 \mathrm{a}_{2} \mathrm{~b}_{3}$ & 7 & 7.6 \\
8 & $5.4 \mathrm{a}_{3} \mathrm{~b}_{2}$ & 8 & 8.9 \\
9 & $5.7 \mathrm{c}_{3} \mathrm{~b}_{1}$ & 9 & 9.0 \\
10 & $4.4 \mathrm{c}_{1} \mathrm{~b}_{4}$ & 10 & 7.9 \\
11 & $5.8 \mathrm{c}_{2} \mathrm{~d}_{1}$ & 11 & 8.9 \\
12 & $5.4 \mathrm{c}_{4} \mathrm{~d}_{3}$ & & \\
13 & $4.3 \mathrm{e}_{1} \mathrm{~d}_{2}$ & & \\
14 & $8.6 \mathrm{e}_{2}$ & & \\
15 & 7.8 & & \\
16 & 11.1 & & \\
17 & 3.5 & & \\
18 & 4.8 & & \\
19 & 6.1 & & \\
\hline
\end{tabular}

this reflects the scarcity of ultrastructural investigations of the early zygotene stage in autopolyploid higher plants rather than a functionally different mechanism of recognition and SC formation. This contention is supported by the results of the spreading analysis of chromosome pairing in tri- and tetraploid Allium. Although distinct stretches of double $\mathrm{SC}$ were not detected either in triploid (25) or in tetraploid Allium (24) at early zygotene or pachytene, the observed pairing pattern comfirms both the existence of specialized association/recognition sites and their potential for specific recognition of more than one homologue. Both trivalents and quadrivalents exhibited a number of associations aligning unpaired chromosomes with their homologues paired with an SC, i.e., a pairing pattern identical to that reported for triploid (34) silkworm oocytes and found in tetraploid spermatocytes.

The pattern of SC formation in both diploid and tetraploid Bombyx spermatocytes indicates that competence for $\mathrm{SC}$ formation between two chromosomes is first aquired at the initial association/recognition sites and proceeds from there in both directions. The rate of SC formation may depend upon the preceding events which make the LCs competent to form an SC.

The notion that recognition, aquirement of LC competence and SC formation are separate events of synapsis is supported by the pairing behaviour of the aberrant tetraploid silkworm male described in section 3.6. Considering that the nuclei of this animal contain four copies of each homologue, the observed number of bivalents ( $1-10$ or a mean of $5 \%$ of all chromosomes) at about $50 \%$ pairing, is remarkably small. At a similar stage of pairing virtually all the chromosomes are homologously paired or associated in diploid $(96 \%, 16)$ and in normal tetraploid nuclei (94\%). Even in the two animals carrying a reciprocal translocation, which in a tetraploid organism would be expected to constitute a particularly difficult pairing problem, associations involving 5 or 7 homologously paired chromosomes were found in most of the nuclei 
(Tables II-IV): evidently, the conditions for specific pairing in the aberrant tetraploid animal were far from optimal during early zygotene.

Only a mean of $9 \%$ of the chromosomes were present as univalents, i.e., approximately the same number as in normal tetraploid nuclei, implying that sufficient chromosome movements had occurred to bring most of the chromosomes into proximity although apparently at a time when the LCs were already competent for $\mathrm{SC}$ formation. The random contacts between recognition sites effected by the chromosome movements at zygotene $(31,40)$ which are preserved only if they have occurred between homologous sites in normal meiosis, apparently resulted in immediate $\mathrm{SC}$ formation in the aberrant spermatocytes even when the associated recognition sites were nonhomologous. The pairing behaviour in the aberrant animal thus indicates that the meiotic defect responsible for the prevalent unspecific SC formation lies in the regulation of the timing of SC formation relative to the achievement of stable associations between homologous recognition sites.

It has been shown in Lilium (reviewed in 41) that the delay of the zygotene DNA replication is mediated by the temporary binding of a $73,000 \mathrm{kD}$ protein, the so-called L-protein (17), to the zygotene DNA sequences. This binding effectively delays replication of the zygotene DNA over the entire premeiotic S-phase until the onset of the zygotene stage. If the ability to engage in SC formation and replication of the zygotene DNA are causally related events, as proposed by Holm (14) and HASENKAMPF (13), then the release of the L-protein from the zygotene DNA sequences may be the controlling factor in the temporal relation between recognition and SC formation at early zygotene. If so, a precocious release of the L-protein from the zygotene DNA sequences in the aberrant tetraploid spermatocytes could account for the breakdown of the mechanism which normally ensures that the initiation of SC formation is delayed until associations are present only between homologous recognition sites.

This sequence of events readily explains the temporal separation of homologous and nonhomologous pairing observed in triploids and in rearrangement heterozygotes (reviewed in 48 ) if the chromosomal changes (replication of zygotene DNA) conferring competence to form an SC, progress to completion during mid and late zygotene whether or not the LCs are associated. Direct experimental evidence in support of this idea is provided by the presence of central region material in unpaired LC segments of several pachytene trivalents in triploid Coprinus (Figures 2 and 5 in 38), in synapsing homologues of the ascomycete Neottiella (47) and can be inferred from the pairing behaviour in spermatocytes of the rodent Ellobius, heterozygous for ten Robertsonian translocations (3). In the latter case, multiple chromosome associations form during late zygotene through SC formation between the two nonhomologous LC segments left unpaired after the initial specific pairing of the translocation chromosomes (which lack the short arms of the pairs of acrocentric chromosomes from which they are derived). The resultant chromosome chains with alternating homologous and nonhomologous SC formation comprise an intermediate situation between normal homologous pairing and the unspecific pairing seen in the aberrant Bombyx male. The extreme situation encountered in haploid organisms where all recognition sites are nonhomologous shows that LC competence and subsequent SC formation can progress to a point where about $60 \%$ of the complement is paired with an SC (9).

\subsection{Formation and resolution of quadrivalents}

The number of quadrivalents in tetraploid Bombyx spermatocytes decreases from a mean of 13.3 at mid-late zygotene to 8.7 at pachytene. At the same time the frequency of bivalents increases from 25.1 to 37.0 (Table VII). The frequencies of bivalents and quadrivalents at metaphase I reported by KAWAGUCHI (18) amounted to 42.15 and 6.7, respectively, and thus demonstrate a further reduction of the quadrivalent frequency with a concomitant increase in bivalent frequency. Except for mid-late zygotene nuclei with means of one univalent and 0.7 trivalents (reflecting yet incomplete pairing), the frequency of univalents and trivalents are negligible or zero in tetraploid spermatocytes. 
Table VII. Frequency of different chromosome associations in tetraploid Bombyx spermatocytes and oocytes.

\begin{tabular}{|c|c|c|c|c|}
\hline Stage & Univalents & Bivalents & Trivalents & Quadrivalents \\
\hline \multicolumn{5}{|l|}{ Spermatocytes } \\
\hline 66- $95 \%$ pairing & 1.0 & 25.1 & 0.7 & 13.3 \\
\hline 95-99\% pairing & 0.2 & 31.5 & 0.0 & 11.1 \\
\hline $99-100 \%$ pairing & 0.0 & 37.0 & 0.0 & $8: 7$ \\
\hline Metaphase I' & 0.45 & 42.15 & 0.05 & 6.7 \\
\hline \multicolumn{5}{|l|}{ Oocytes $^{2}$} \\
\hline Early pachytene & 2.0 & 36.7 & 0.7 & 8.4 \\
\hline Mid-late pachytene & 1.4 & 51.9 & 0.6 & 0.9 \\
\hline
\end{tabular}

1) Data from (18). 2) Data from (36).

This demonstrates that only about $50 \%$ of the quadrivalents initially formed during zygotene survive up to metaphase I, the remaining $50 \%$ being converted into bivalents between zygotene and metaphase I. Previous reconstruction analysis of tetraploid Bombyx oocytes (36) revealed 8.4 quadrivalents and 36.7 bivalents per nucleus at early pachytene i.e., frequencies identical to those determined for tetraploid spermatocytes at pachytene, while at late pachytene only 0.9 quadrivalents but 51.9 bivalents were present in the oocytes (Table VII). Almost total conversion of quadrivalents into bivalents thus occurs in the female whereas only about $50 \%$ of the quadrivalents convert into bivalents in the male. This remarkable sex dependent difference in the behaviour of multivalents during the meiotic prophase between the recombination proficient male and the recombination deficient, achiasmatic female establishes definitively that the occurrence of crossing over at pachytene in the male prevents further conversion of quadrivalents into bivalents. This constraint is absent during pachytene in the female thus enabling an almost complete conversion of multivalents into bivalents prior to the onset of the postpachytene modification of the SCs required to maintain the bivalents up to metaphase I in the absence of chiasma formation (33).

In addition to providing experimental support for our earlier conclusion on the effect of crossing over on the correction of chromosome pairing $(34,36,48)$, the present data justify a more detailed analysis and discussion of the formation and fate of quadrivalents in autote- traploids, a subject which has received considerable attention both in classical cytogenetic studies $(7,23)$ and in more recent light microscopical $(5,22,2829,45$ and literature cited herein) and ultrastructural $(9,10)$ investigations. Comparative analyses at zygotene or pachytene and metaphase I in autotetraploids of the nematodes Heterodera (11) and Meloidogyne (12), autotetraploid Allium porrum (23) and the autotetraploid Bombyx female (36) illustrate that regular bivalent formation at metaphase $I$ can be achieved by at least three fundamentally different mechanisms: 1)In tetraploid nematodes exclusive bivalent formation occurred at pachytene, each SC being anchored to the nuclear envelope at one end only. This suggests that initial recognition and SC initiation at the beginning of zygotene are confined to a single region in each bivalent, which would effectively prevent exchange of pairing partner and thus ensure exclusive bivalent formation at zygotene. 2) In autotetraploid Allium porrum (23) quadrivalents were readily observed at pachytene, and in some nuclei all 32 chromosomes were paired into 8 quadrivalents. None the less, only bivalents were present at metaphase I, each bivalent having two chiasmata one at each side of the centromere. In this case, regular bivalent formation is achieved by strict control of the number and localised distribution of crossovers and chiasmata. Only the few quadrivalents in which the exchange of pairing partner separates the two adjacent chiasmata on either side of the centromere will survive up to metaphase I ( 10 in 380 cells compared to $1-5$ per cell in other autote- 
traploid Allium without chiasma localisation). Resolving quadrivalents were observed at diakinesis confirming this conclusion but also showing that - even with a localisation of the two crossovers per bivalent - a conversion of quadrivalents into bivalents at pachytene did not contribute significantly to the reduction of the quadrivalent frequency. 3) The autotetraploid Bombyx female (36) finally exemplifies a situation where quadrivalents form during zygotene and where complete pairing correction at early pachytene alone accounts for the elimination of quadrivalents.

The interpretation of the pairing behaviour at metaphase $I$ is less straightforward in autotetraploid organisms with two or more recognition sites per chromosome and where crossing over and chiasma formation are not confined to specific regions. An extensive analysis of chromosome associations at metaphase $I$ in a number of autotetraploid plants $(28,29)$ revealed a considerable variation from cell to cell but a remarkably similar mean frequency of quadrivalents in nearly all the species analysed, close to the frequency expected (67\%) from random pairing initiation at both ends of associated chromosome sets with no subsequent pairing correction. A similar correspondence between the observed and the expected random frequency at metaphase I was also reported for the isogenic tetraploid (a successively chromosome doubled haploid) barley (5) and to a lesser extent for autotetraploid Triticum monococcum (see discussion in 10).

The pairing pattern at metaphase $I$ in autotetraploid Hyoscyamus (22) on the other hand showed preferential bivalent formation, involving $72 \%$ of the chromosomes (the quadrivalent frequency at pachytene was not determined) as has also been reported for autopolyploids of Chrysanthemum (45) and Allium vineale (24). In the latter species, the quadrivalent frequency determined at pachytene amounted to $80 \%$ whereas only $22 \%$ of the homologues formed quadrivalents at metaphase I, possibly due to a low chiasma frequency (24). These observations indicate that, except for the preferential bivalent formation at zygotene described in nematodes $(11,12)$ and proposed to account for the regular bivalent formation in polyploid Chrysanthe- mum (45), multivalents are present at pachytene at frequencies approaching or even exceeding the $67 \%$ expected from random telomeric initiation in associated homologous chromosome groups. The final pairing pattern at metaphase I in most of the autotetraploid plant species investigated thus appears to be determined primarily by the number and distribution of crossovers and chiasmata. This is in contrast to the situation in tetraploid Bombyx spermatocytes where the conversion of quadrivalents into bivalents before crossing over is the main source of the reduction in multivalent frequency.

A critical parameter in this context may be the duration of the interval between completion of SC formation and the occurrence of crossing over. The conditions for pairing correction may be less favorable than those existing in autotetraploid Bombyx in the following situations: 1) If the time available for pairing correction is short as is indicated for allohexaploid wheat where SC formation rarely if ever reaches completion before diplotene elimination of the SCs commences (15). 2) If long chromosomes with multiple initiation sites for SC formation, as is commonly found in plants $(13,14,15,24,25)$, lead to multiple exchanges of pairing partner.

\subsection{Concluding remarks}

The ultrastructural analysis of chromosome pairing in diploid and polyploid males and females of the silkworm have provided a detailed picture of the basic events of meiotic prophase $(16,32-37)$. This information has been compiled in the flow-chart shown in Figure 13 which covers the period from the completion of the premeiotic DNA replication until the completion of pairing and SC formation at pachytene. The upper half of the diagram includes the initial specific alignment of homologous chromosomes and the proposed temporal relation between homologue recognition and initiation of SC formation. The lower part of the diagram describes the progression and completion of SC formation, during which interlockings are resolved, exchanges of pairing partners eliminated through turnover of the central region of the SC and inequalities of $\mathrm{LC}$ lengths in structurally heterozygous chromosome complements are 
S. W. RASMUSSEN: Synapsis in tetraploid Bombyx

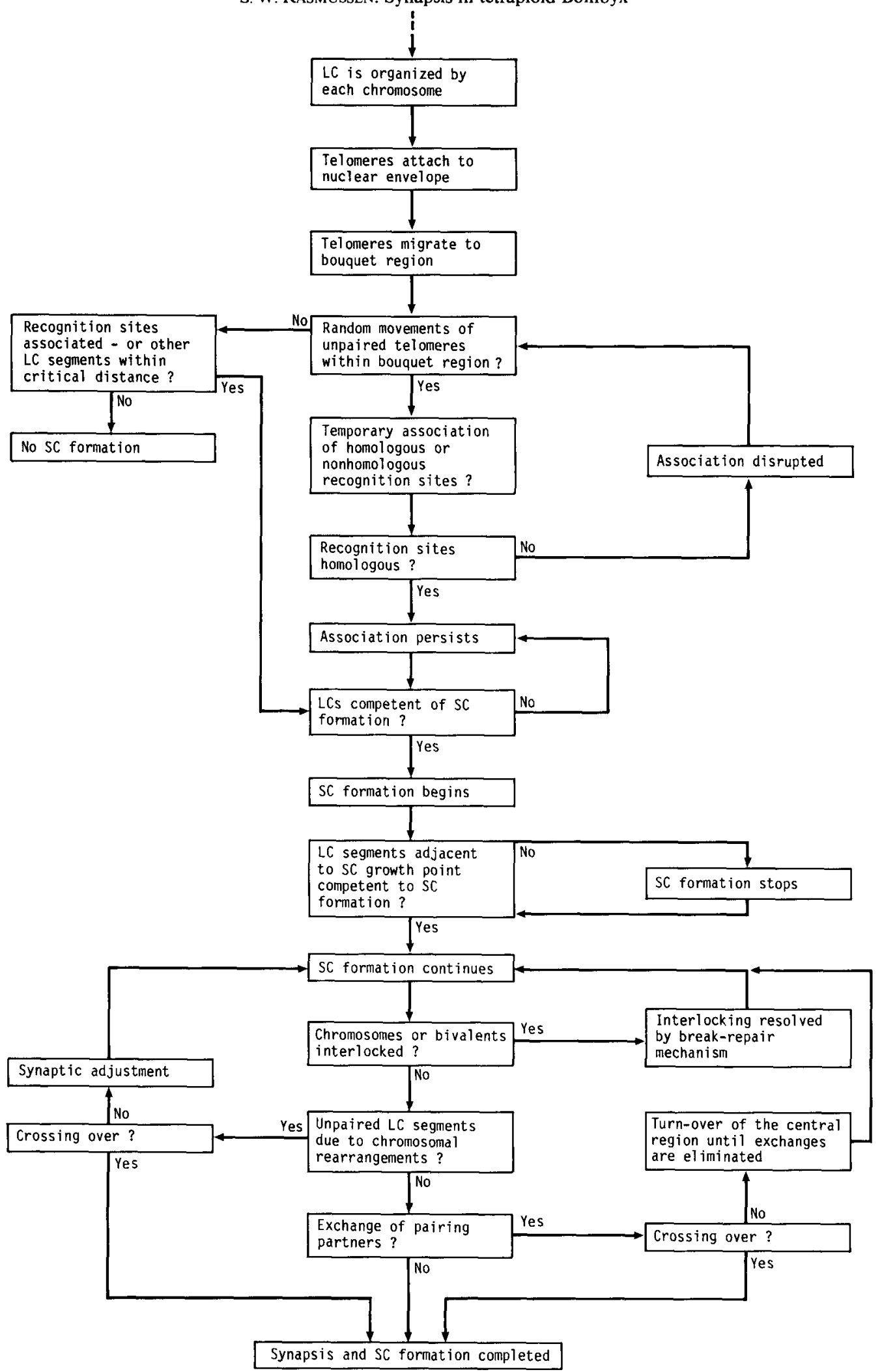

Figure 13. Flow-chart of synapsis and SC formation during the meiotic prophase in the male silkworm. 
accommodated through synaptic adjustment. The latter process has not been unambiguously identified in the silkworm but has been described in a number of other species, mainly in rodents (see 30 for a general review). The effect of crossing over on synaptic adjustment is at present somewhat unclear; in a number of cases crossing over has been shown to prevent subsequent adjustment (48) while in others, synaptic adjustment has been shown to occur inspite of crossing over and chiasma formation for example within the inverted segment in heterozygotes for pericentric inversions (30).

With this limitation the diagram shows that rather than a single consecutive series of events, early meiotic prophase comprises a set of dynamic processes which, in addition to ensuring recognition and SC formation between homologous chromosomes, resolve interlockings (and possibly also the less fatal chromosome intertwinings) through controlled breakage and repair of entire chromosomes, remove or reduce pairing irregularities in the form of pairing partner exchanges and, through specific or nonspecific SC formation, minimize the frequency of univalents.

\section{ACKNOWLEDGEMENTS}

It is a pleasure to thank Prof. D. voN WetTSTEIN and Drs. P.B. Holm and D.J. SimPSON for many discussions during the course of this work and for their critical review of the manuscript. The expert technical assistance of Jean Sage. Bibi Andersen, Ann-Sofi SteinHOLTZ and NinA RASMUSSEN is gratefully acknowledged. The work was financially supported by grant BI6-168-DK from the Commission of the European Communities.

\section{REFERENCES}

1. Astaurov, B. L.: Experimental polyploidy in animals. Ann. Rev. Genet. 3, 99-126 (1969)

2. Astaurov, B. L.: Experimental alterations of the developmental cytogenetic mechanisms in mulberry silkworms: artificial parthenogenesis, polyploidy, gynogenesis, and androgenesis. Adv. Morphogen. 6, 199-257 (1967)

3. Bogdanov, Yu. F., O. L. Kolomiets, E. A. LyaPUNOVA, I. YU. YaNinA \& T. F. MAZUROVA: Synap- tonemal complexes and chromosome chains in the rodent Ellobius talpinus heterozygous for ten Robertsonian translocations. Chromosoma 94, 94-102 (1986)

4. BYers, B. \& L. Goetsch: Electron miscoscopic observations on the meiotic karyotype of diploid and tetraploid Saccharomyces cerevisiae. Proc. Nat. Acad. Sci. USA 72, 5056-5060 (1975)

5. Callow, R.S., Y. Hamey \& S. M. Pattrick: Pairing of identical chromosomes in an isogenic tetraploid. Heredity 53, 107-111(1984)

6. Comings, D. E. \& T.A. OKaDA: Triple chromosome pairing in triploid chickens. Nature 231, 119-121 (1971)

7. Darlington, C. D.: Recent Advances in Cytology. 2nd. ed. Churchill, London pp. 671 (1937)

8. Dollin, A. E. \& J. D. Murray: Triple chromosome pairing in an aneuploid bull spermatocyte. Can. J. Genet. Cytol. 26, 782-783 (1984)

9. Gillies, C. B.: The synaptonemal complex in higher plants. CRC Critical Rev. Plant Sci. 2, $81-116$ (1984)

10. Gillies, C. B., J. Kuspira \& R. N. Bhambhani: Genetic and cytogenetic analyses of the A genome of Triticum monococcum. IV Synaptonemal complex formation in autotetraploids. Genome 29 (in press) (1987)

11. Goldstein. P. \& A. C. Triantaphyllou: Karyotype analysis of the plant parasitic nematode Heterodera glycines by electron microscopy. II. The tetraploid and an aneuploid hybrid. J. Cell Sci. 43, 225-237 (1980)

12. Goldstein.P.\& A.C. Triantaphyllou: Pachytene karyotype analysis of tetraploid Meloidogyne hapla females by electron microscopy. Chromosoma $82,405-412$ (1981)

13. Hasenkampf, C. A.: Synaptonemal complex formation in pollen mother cells of Tradescantia. Chromosoma 90, 275-284 (1984)

14. Holm, P. B.: Three dimensional reconstruction of chromosome pairing during the zygotene stage of meiosis in Lilium longiflorum (Thunb. ). Carlsberg Res. Commun. 42, 103-151 (1977)

15. Holm, P. B.: Chromosome pairing and chiasma formation in allohexaploid wheat, Triticum aestivum analyzed by spreading of meiotic nuclei. Carlsberg Res. Commun. 51, 239-294 (1986)

16. Holm, P. B. \& S. W. Rasmussen: Chromosome pairing, recombination nodules and chiasma formation in diploid Bombyx males. Carlsberg Res. Commun. 45, 483-548 (1980)

17. Hotta, Y., S. Tabata \& H. Stern: Replication and nicking of zygotene DNA sequences. Control by a meiosis-specific protein. Chromosoma 90, 243 253 (1984) 
18. KaWAGUCHI, E.: Der Einfluss der Eierbehandlung mit Zentrifugierung auf die Vererbung bei dem Seidenspinner. II. Zytologische Untersuchung bei den polyploiden Seidenspinnern. Cytologia (Tokyo) 9, 38-54 (1938)

19. KawamuRA, N: The early embryonic mitosis in normal and cooled eggs of the silkworm, Bombyx mori. J. Morph. 158, 57-71 (1978)

20. Kawamura, N.: Polyploidy and size of serosa nuclei and cells in eggs of the silkworm, Bombyx mori. J. Sericult. Sci. Japan 48, 77-85 (1979)

21. Kawamura, N.: The induction of hexaploid and octoploid specimens in the silkworm (Bombyx mori) by exposing to low temperature. Proc. Jap. Acad. 57 ser. B, 77-82 (1981)

22. Lavania. U.C.: High bivalent frequencies in arificial autopolyploids of Hyoscyamus muticus L. Can. J. Genet. Cytol. 28, 7-11 (1986)

23. Levan, A.: Meiosis in Allium porrum, a tetraploid species with chiasma localisation. Hereditas 26 , 454-462 (1940)

24. LOIDL, J.: Synaptonemal complex spreading in Allium. II. Tetraploid A. vineale. Can. J. Genet. Cytol. 28, 754-761 (1986)

25. LOIDL, J. \& G. H. Jones: Synaptonemal complex spreading in Allium I. Triploid A. sphaerosephalon. Chromosoma 93, 420-428 (1986)

26. MAEDA. T.: Chiasma studies in the silkworm, Bombyx mori L. Japanese J. Genet. 15, 118-127 (1939)

27. MOENS, P. B.: Research needs in meiosis, mechanisms of synapsis, and chiasma regulation. In: Aneuploidy. V. L. Dellarco, P. E. Voytek \& A. Hollaender, eds. Plenum Publishing Corp., $397-$ 407 (1985)

28. Morrison, J. W. \& T. Rajhathy: Chromosome behaviour in autotetraploid cereals and grasses. Chromosoma 11, 297-309 (1960)

29. Morrison, J. W. \& T. Rajhathy: Frequency of quadrivalents in autotetraploid plants. Nature $187,528-530(1960)$

30. Moses, M. J., M. E. Dresser \& P. A. Poorman: Composition and role of the synaptonemal complex. In: Controlling Events in Meiosis. C. W. Evans \& H. G. Dickinson, eds. Symp. Soc. Exptl. Biol. 38, 245-270 (1984)

31. Parvinen, M. \& K -O. Söderstrom: Chromosome rotation and formation of synapsis. Nature 260 , 534-535 (1976)

32. Rasmussen, $\mathbf{S}$. W.: The meiotic prophase in Bombyx mori females analyzed by three-dimensional reconstructions of synaptonemal complexes. Chromosoma 54, 245-293(1976)

33. Rasmussen, $S$. W.: The transformation of the synaptonemal complex into the "elimination chromatin" in Bombyx mori oocytes. Chromosoma 60, 205-221 (1977)

34. RASMUSSEN, $\mathrm{S}$. W.: Chromosome pairing in triploid females of Bombyx mori analyzed by three-dimensional reconstructions of synaptonemal complexes. Carlsberg Res. Commun. 42, 163-197 (1977)

35. RASMUSSEN, S. W.: Initiation of synapsis and interlocking of chromosomes during zygotene in Bombyx spermatocytes. Carlsberg Res. Commun. 51, 401-432 (1986)

36. Rasmussen. S. W. \& P. B. Holm: Chromosome pairing in autotetraploid Bombyx females. Mechanism for exclusive bivalent formation. Carlsberg Res. Commun. 44, 101-125 (1979)

37. Rasmussen, S. W. \& P. B. Holm: The meiotic prophase in Bombyx mori. In: Insect Ultrastructure. Vol 1. R. C. King \& H. Akai, eds. Plenum Publishing Corp. New York, 61-85 (1982)

38. Rasmussen, S. W., P. B. Holm, B. C. Lu, D. ZiCKLeR \& J. SAGE: Synaptonemal complex formation and distribution of recombination nodules in pachytene trivalents of triploid Coprinus cinereus. Carlsberg Res. Commun. 46, 347-360 (1981)

39. SaKaguchI, B.: Gametogenesis, fertilization and embryogenesis of the silkworm. In: The Silkworm. A Important Laboratory Tool. Y. Tazima, ed., Kodansha, Tokyo, 5-30 (1978)

40. Salonen, K.. J. Paranko \& M. Parvinen: A colcemid-sensitive mechanism involved in regulation of chromosome movements during meiotic pairing. Chromosoma 85, $611-618$ (1982)

41. STERN, H. \& Y. HotTA: Chromosome organization in the regulation of meiotic prophase. In: Controlling Events in Meiosis. C. W. Ewans \& H. G. Dickinson, eds. Symp. Soc. Exptl. Biol. 38, 161175 (1984)

42. Sturtevant. A. H.: No crossing over in the female silkworm moth. Amer. Natur. 49, 42-44 (1915)

43. SvED, J.A.: Telomere attachment of chromosomes. Some genetical and cytological consequences. Genetics 53, 747-756 (1966)

44. Wallace, B. M. N.\& M. A. Hultén: Triple chromosome synapsis in oocytes from a human foetus with trisomy 21 . Ann. Hum. Genet. 47, 271-276 (1983)

45. Watanabe, K.: Studies on the control of diploidlike meiosis in polyploid taxa of Chrysanthemum 4. Colciploids and the process of cytogenetical diploidization. Theor, Appl. Genet. 66, 9-14 (1983)

46. WEITH, A.\& W. Traut: Synaptic adjustment, nonhomologous pairing, and non-pairing of homologous segments in sex chromosome mutants of Ephestia kuehniella (Insecta, Lepidoptera). 
S. W. RASMUSSEN: Synapsis in tetraploid Bombyx

Chromosoma 94, 125-131 (1986)

47. Wetrstein, D. von: The assembly of the synaptinemal complex. Phil. Trans. R. Soc. Lond. B. 277, 235-243 (1977)

48. WetTSTEIN, D. von, S. W. Rasmussen \& P. B. Holm: The synaptonemal complex in genetic segregation. Ann. Rev. Genet. 18, 331-413 (1984)

Accepted by E. LunD 